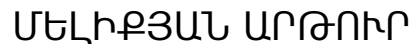

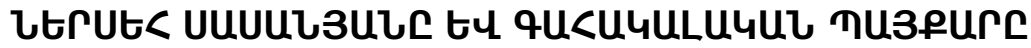

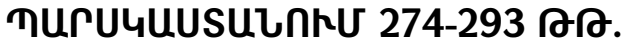

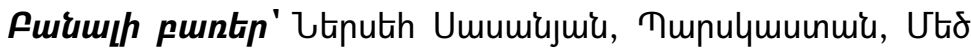

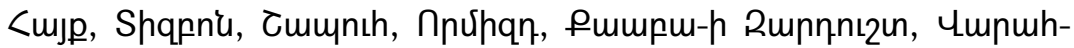
nuiu, <nnu:

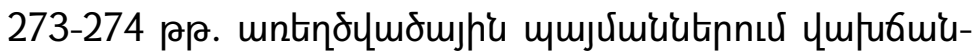

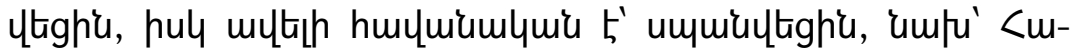

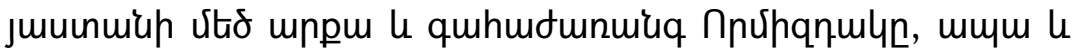

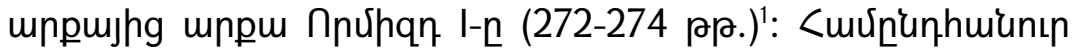

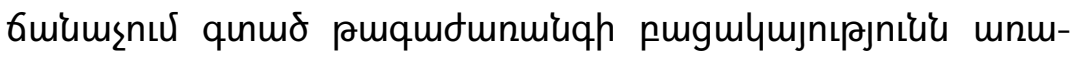

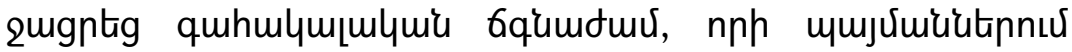

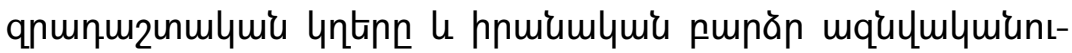

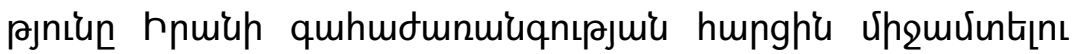
umuntih wnhp unnuguiu:

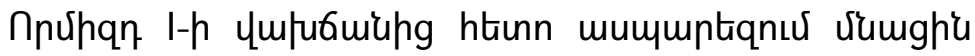

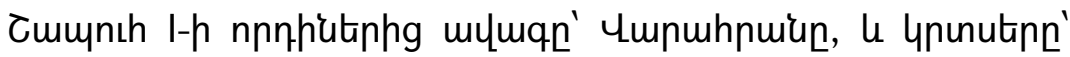

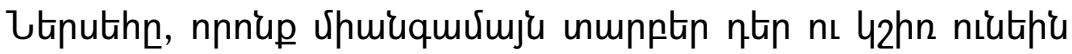

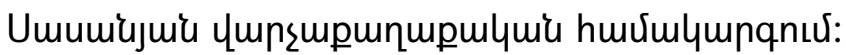

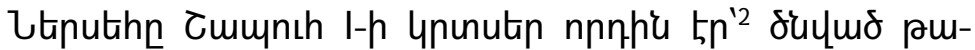

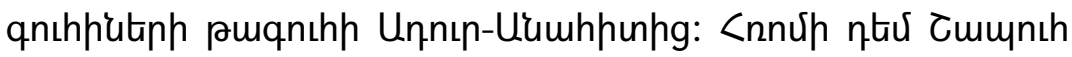

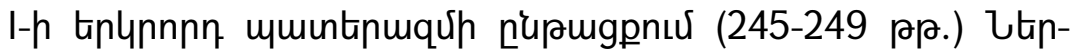

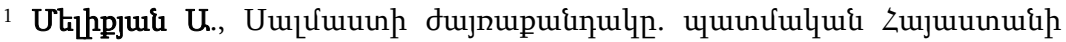

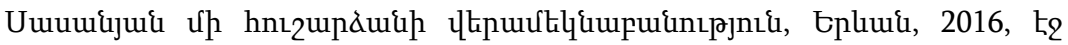
172-174:

${ }^{2}$ Weber U., Wahrām II, König der Könige von Ērān und Anērān, Iranica Antiqua, 2009, № 44, S. 568 .
} 


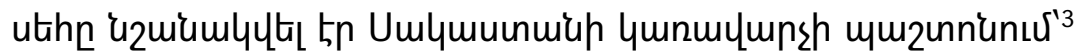

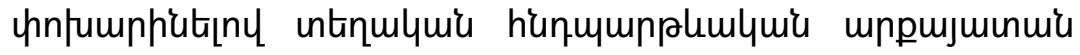

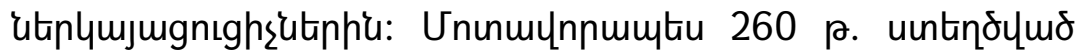

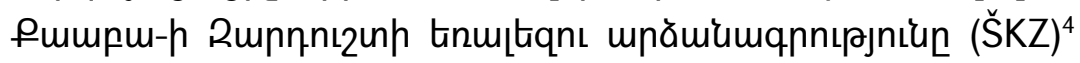

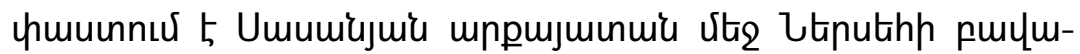

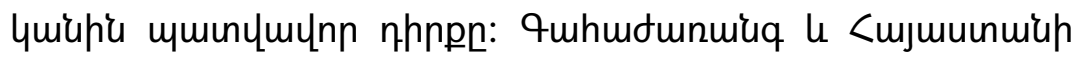

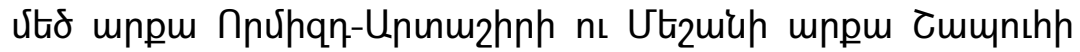

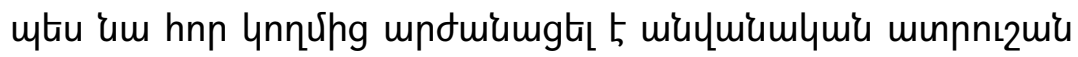

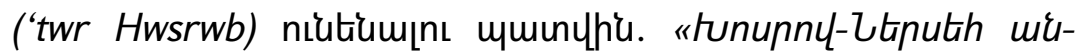

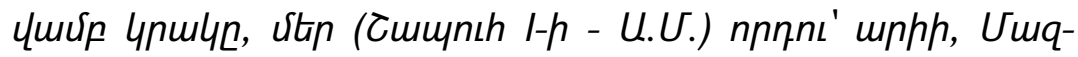

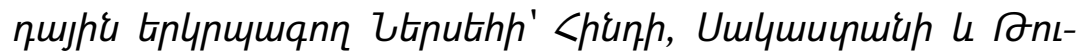

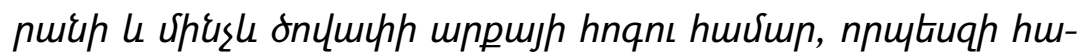

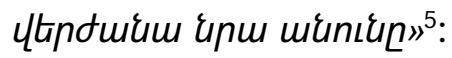

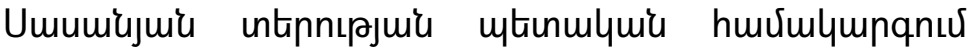

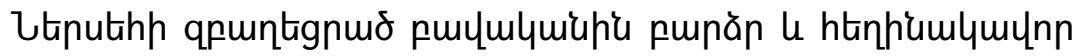

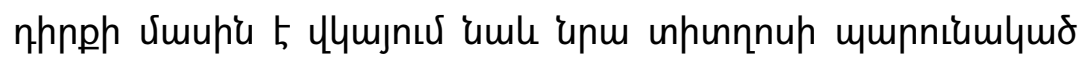

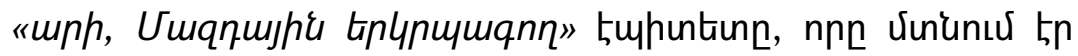

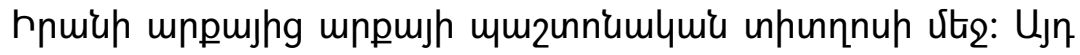

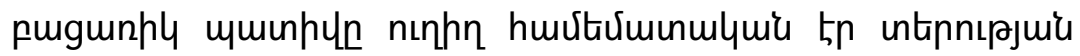

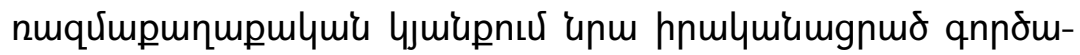

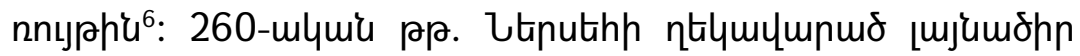

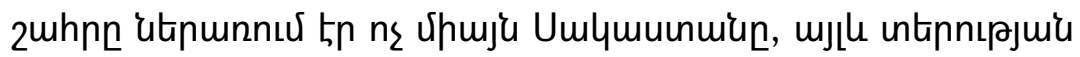

\footnotetext{
3 Луконин В. Завоевания Сасанидов на Востоке и проблема кушанской абсолютной хронологии. ВДИ, 1969, № 1-2, стр. 37.

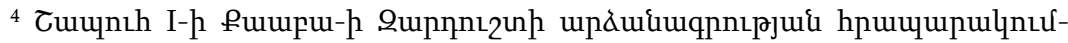
\{tipn unt' u Sprengling M., Third Century, Iran, Sapor and Kartir, Chicago, 1953; Maricg M., Res Gestae divi Saporis, Syria, XXXV, 1956; Huyse Ph., Die dreisprachige Inschrift Šābuhrs I. an der Ka ba-i Zardušt (ŠKZ), 2 vols., Corpus Inscriptionum Iranicarum III, London, 1999, Text I-II.

${ }_{5}^{5}$ ŠKZ, MPers. § 23, 24; Phl. § 19; Gk. § 42.

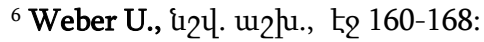




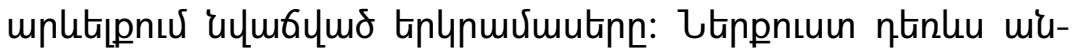

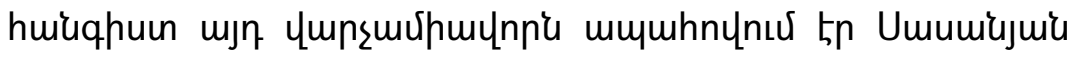

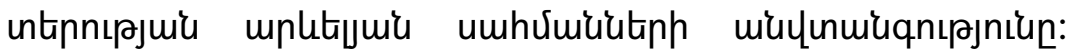

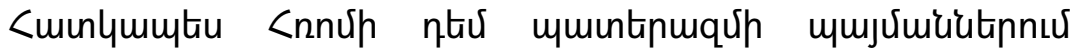

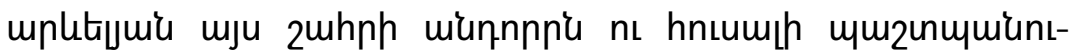

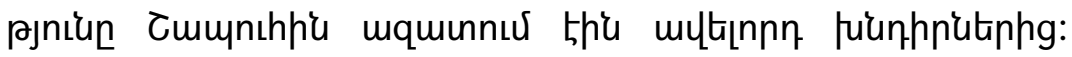

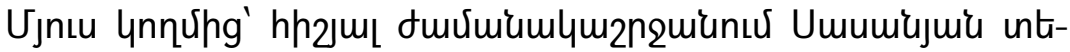

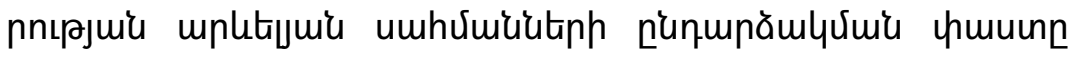

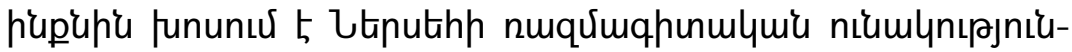

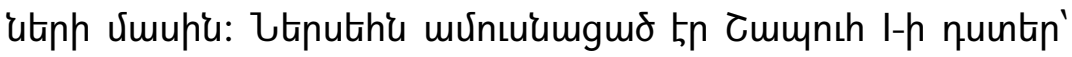

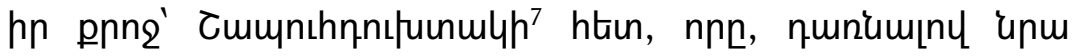

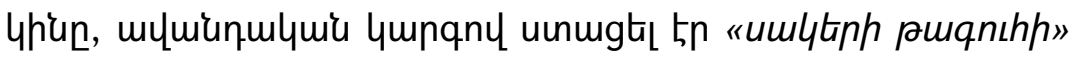
unpunnnun ${ }^{8}$ :

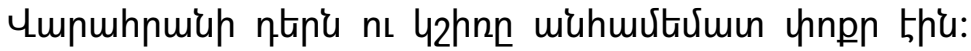

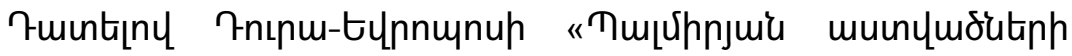

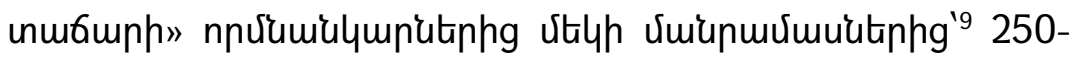

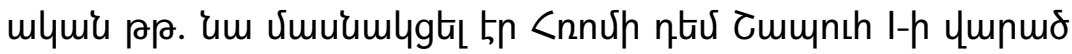

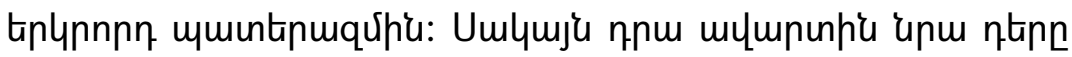

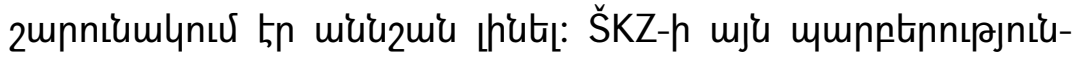

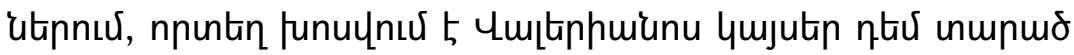

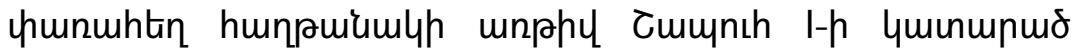

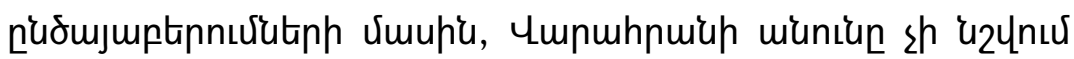

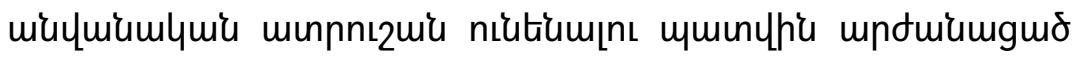

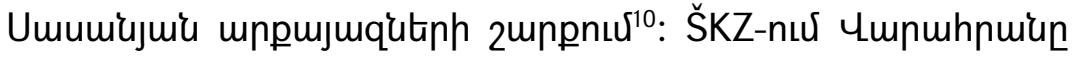

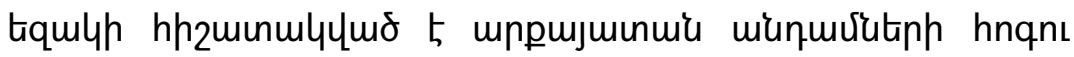

\footnotetext{
7 Луконин В. Культура Сасанидского Ирана, Москва, 1969, стр. 198.

${ }^{8}$ ŠKZ, Phl.' 20-21. šhypwhrdwhtkyh Skn MLKTH.

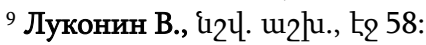

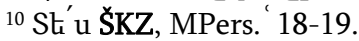




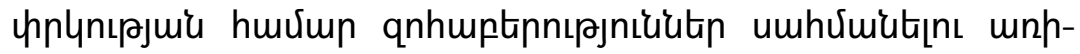

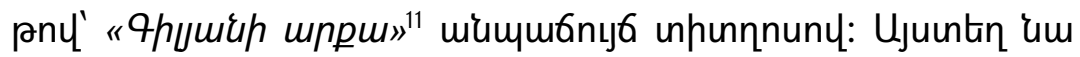

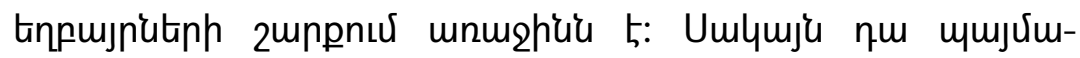

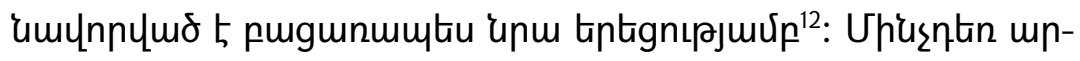

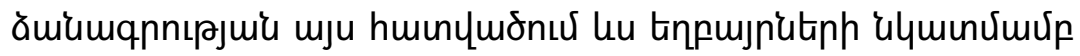

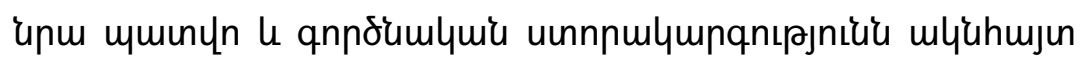

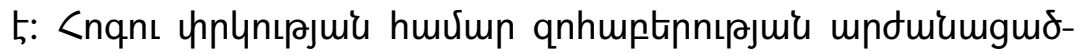
utiph gnıgulynuर quhurumuiuq กnúhqn-Ununuzhnhg pugh

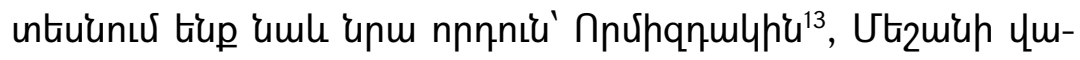

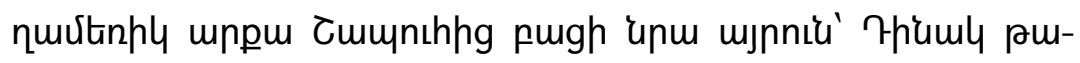

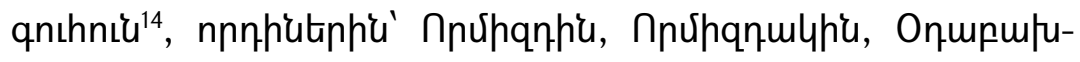

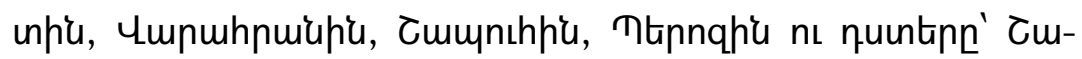

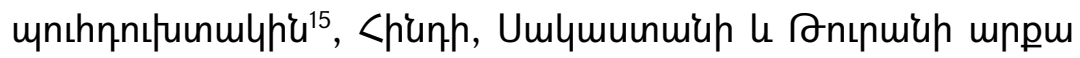

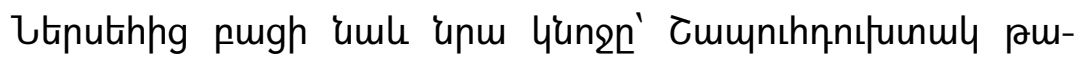

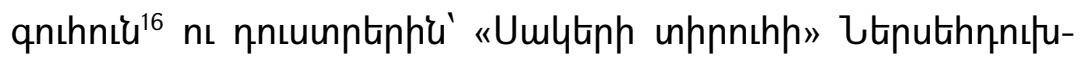

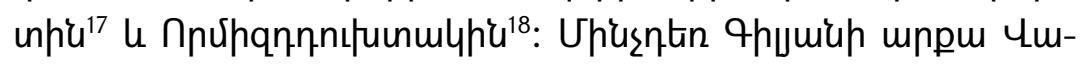

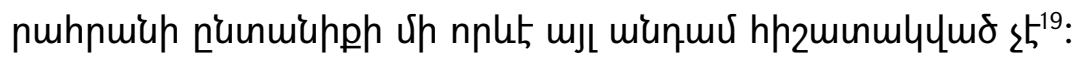

${ }^{11}$ ŠKZ, MPers. '25: wr'hr'n Gyl'n MLK'; Phl. 20. Wryhr'm Gyln MLK'.

${ }^{12}$ Weber U., Narseh, EIr, online edition, 2016, available at

http://www.iranicaonline.org/articles/narseh-sasanian-king (accessed on 23 May 2016).

${ }^{13}$ ŠKZ, MPers $§ 21$.

${ }^{14}$ ŠKZ, MPers $§ 20$.

${ }_{15}$ ŠKZ, MPers $§ 21$.

${ }_{16}$ ŠKZ, MPers § 20- 21.

${ }_{17}^{17}$ ŠZ, Mpers $§ 21$.

18 ŠKZ, Mpers § 21.

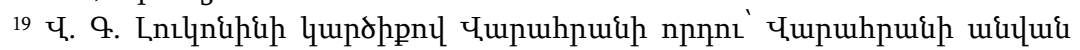

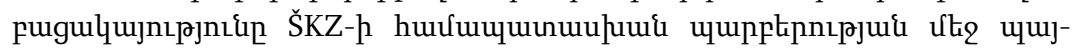

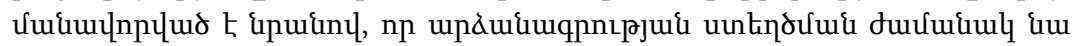

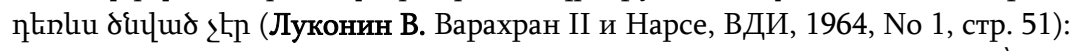

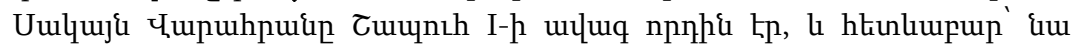




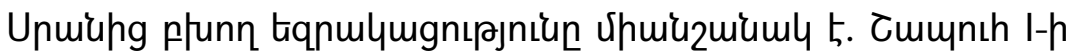

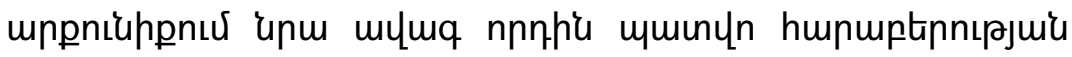

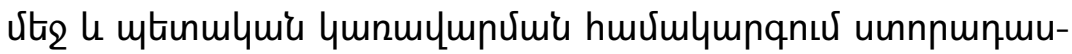

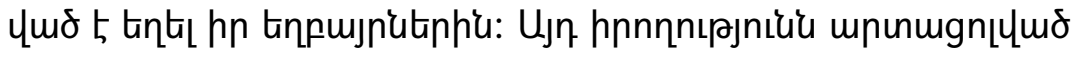

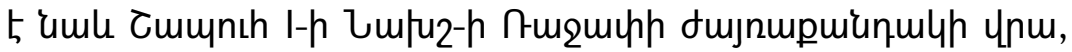

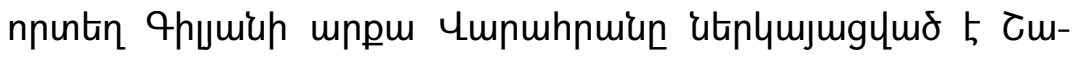
unıhh ujnıu nnnhüitnhg' กnúnqn-Ununuzhnhg, Zmunnhhg $u$

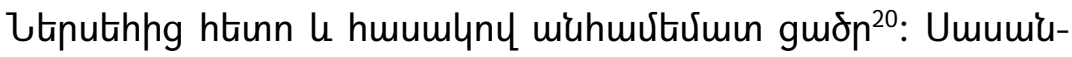

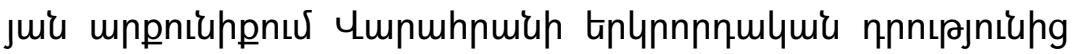

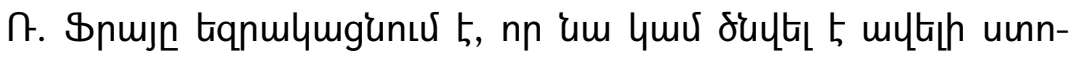

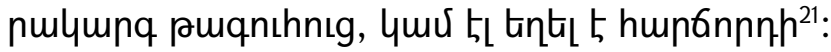

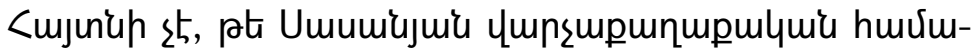

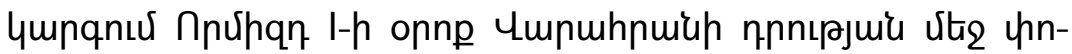

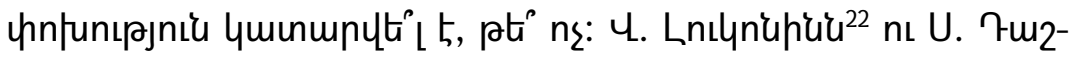

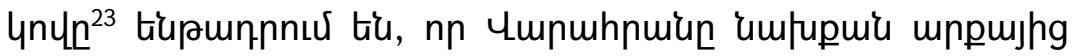

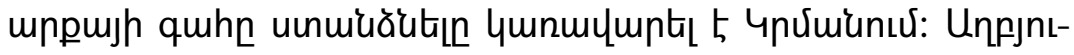

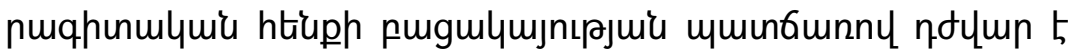

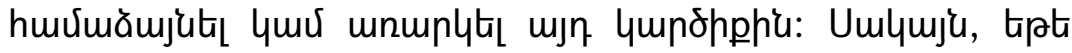

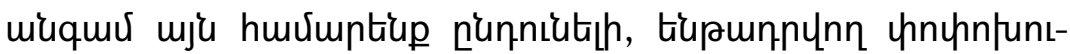

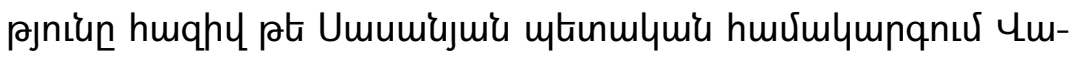

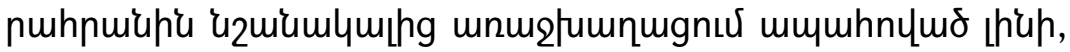

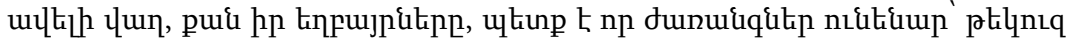
lu hquilumi utinh:

20 Луконин В. Культура Сасанидского Ирана, Москва, 1969, стр. 61, рис. 9.

${ }^{21}$ Frye R.N., The Political History of Iran Under Sasanides, in: Cambridge History of Iran, Vol. 3 (1), Cambridge, 1983, p. 127.

22 Луконин В. Иран в III веке. Москва, 1979, стр. 59.

${ }^{23}$ Дашков С. Цари царей-Сасаниды: Иран III-VII вв. в легендах, исторических хрониках и современных исследованиях. Москва, 2008, стр. 75. 


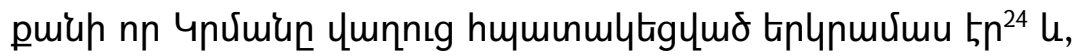

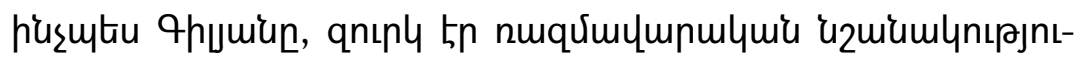
ung:

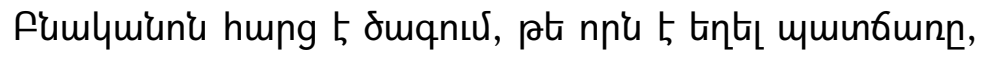

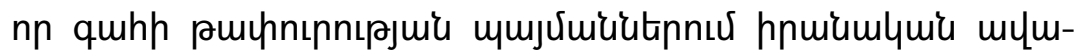

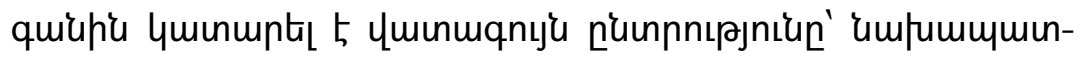

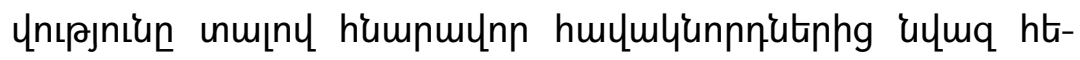

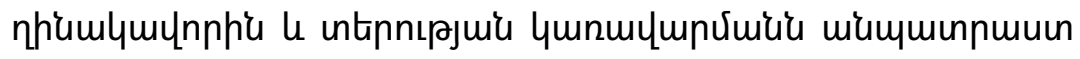

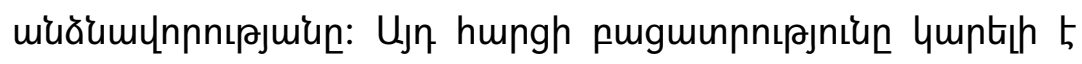

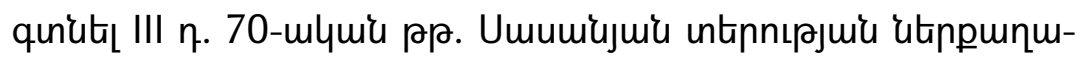

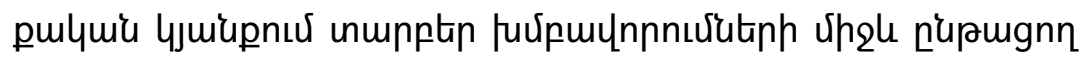

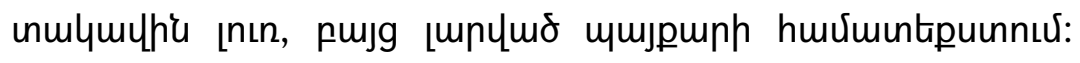

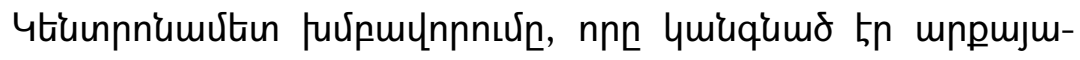

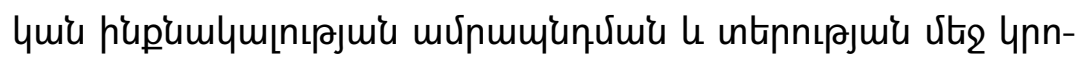

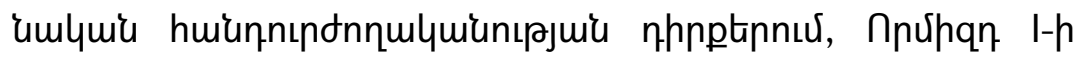

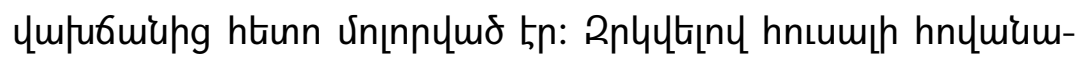

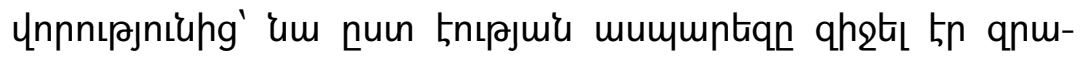

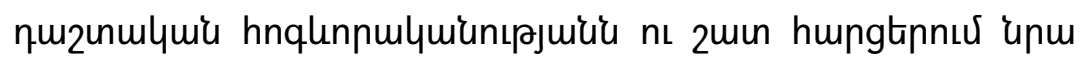

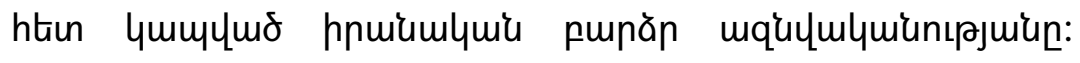

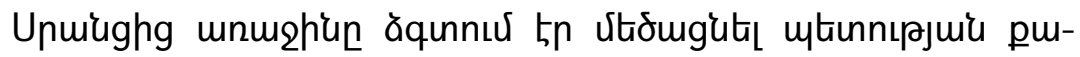

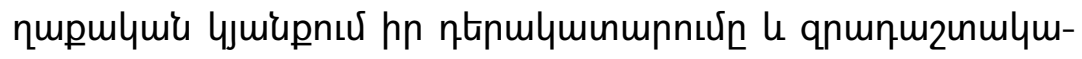

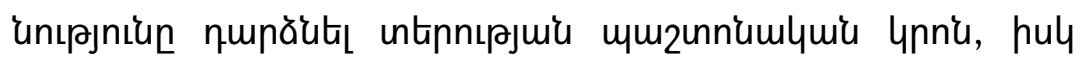

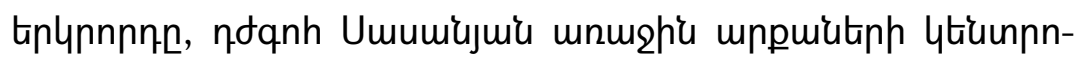

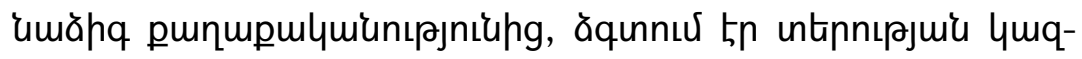

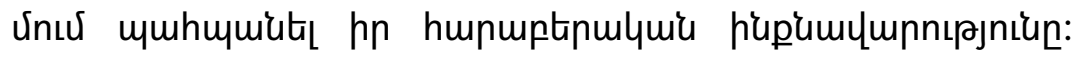

\footnotetext{
${ }^{24}$ Книга деяний Ардашира, сына Папака. Транскрипция текста, перевод со среднеперсидского, введение, коментарий и глоссарий О.М. Чунаковой. Москва, 1987, стр. 72. The History of al-Tabari, Vol. V, The Sasanids, the Byzantines, the Lakhmids, and Yemen, translated and annotated by C. E. Bosworth, New York, 1999, pp. 9-10.
} 


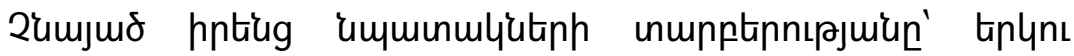

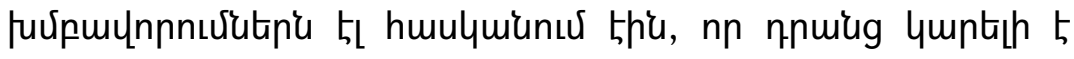

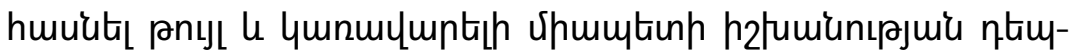

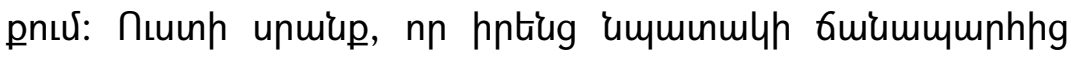

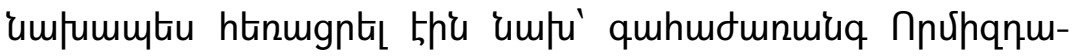

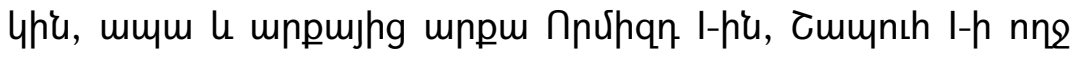

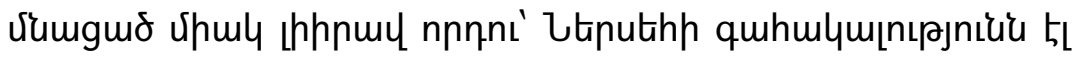

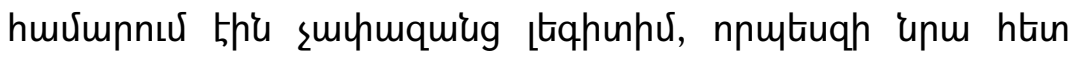

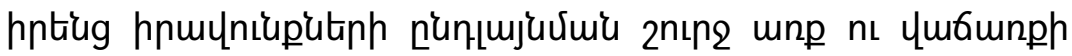

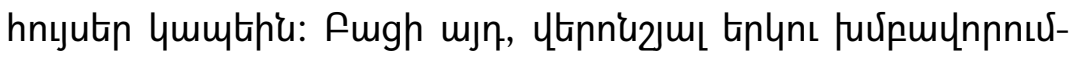

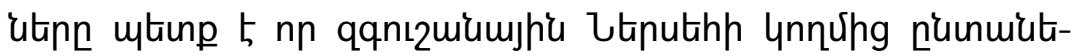

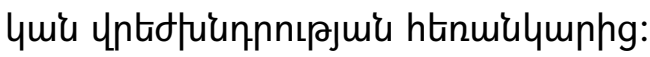

U. Cuptipu nı U. Fpnupniun Utiputihn 2nquiugưuiu

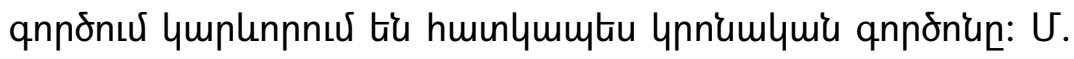

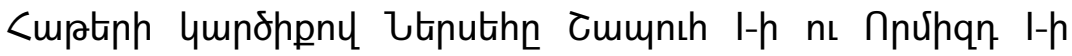

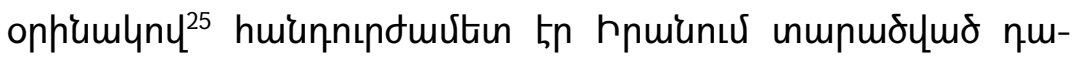

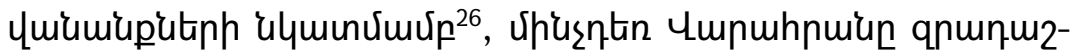

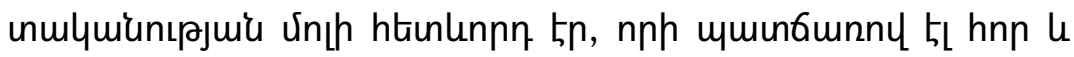

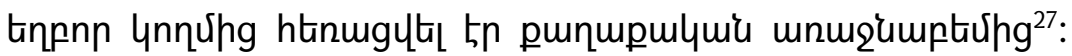

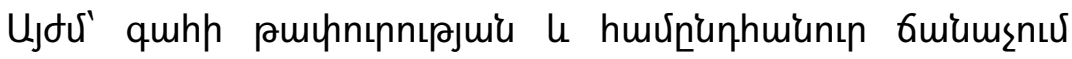

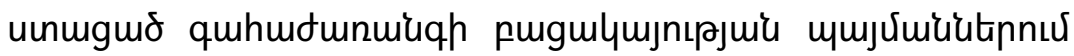

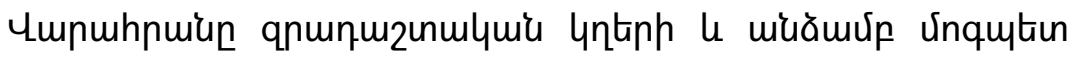

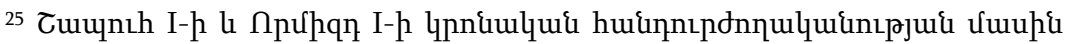
unt' u Hutter M., Manichaeism in the Early Sasanian Empire, Numen, 1993, Vol. 40, No. 1, pp. 6, 11; Виденгрен Г. Мани и манихейство. Санкт-Петербург, 2001, стр. 53-63; Смагина Е. Манихейство по ранним источникам. Москва, 2011, стр. 43-49.

${ }^{26}$ Brosius M., The Persians, New York, 2006, pp. 147-148.

${ }^{27}$ Hutter M., Manichaeism in the Early Sasanian Empire, p. 11; Brosius M., \{2l. u2hu., te 146,147:
} 


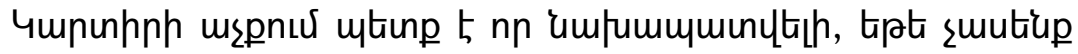

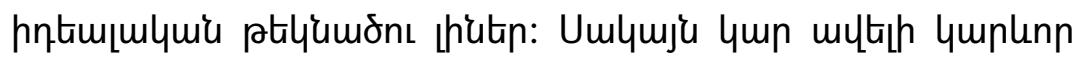

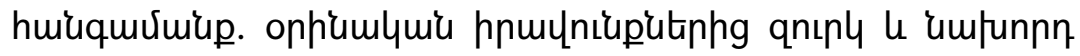

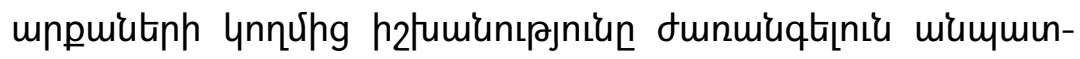

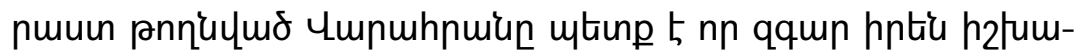

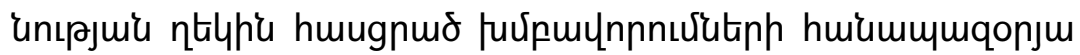

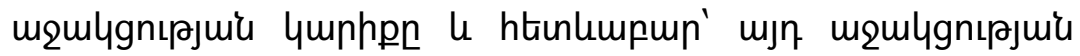

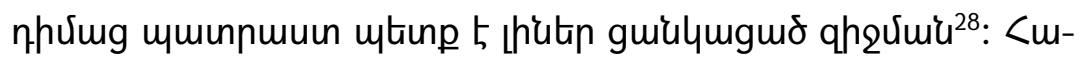

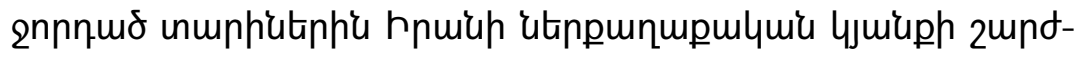

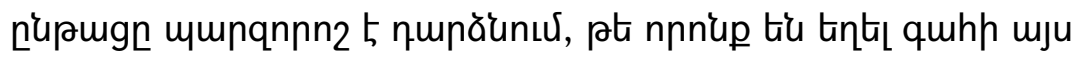

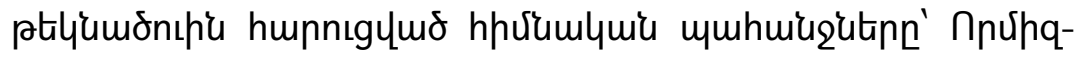

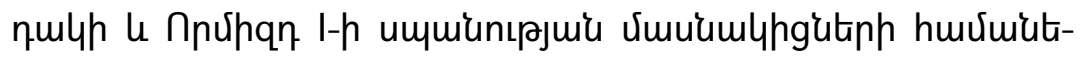

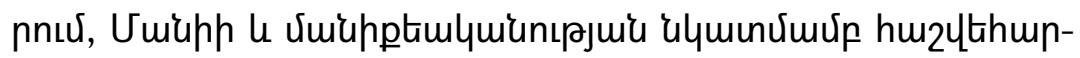

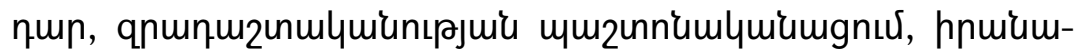

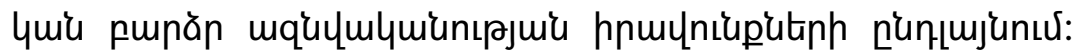

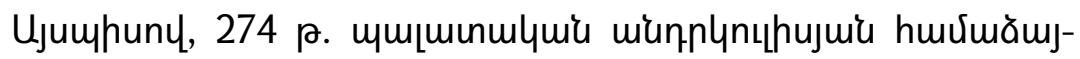

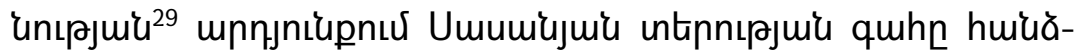

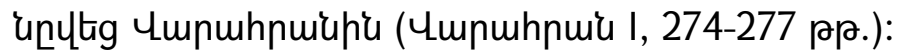

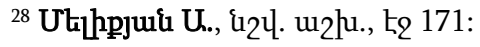

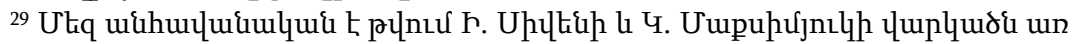

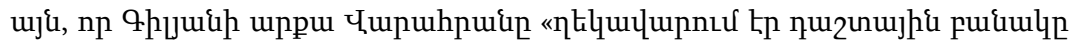
l hp tippn (

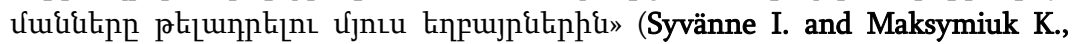
The Military History of the Third Century Iran, Siedlce, 2018, p. 110): Uhliunuja

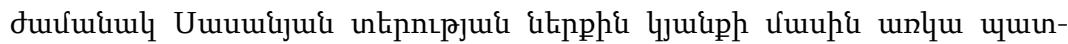

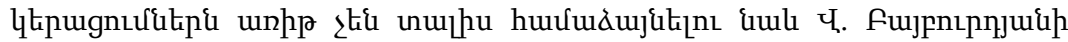

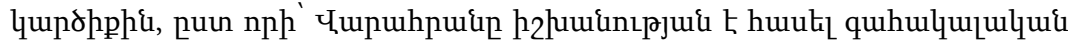

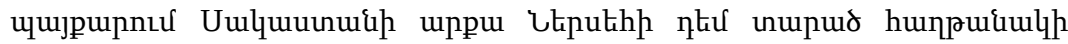

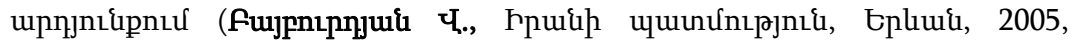
te 123):
} 


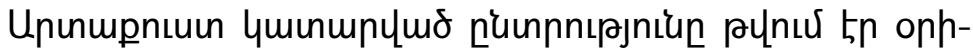

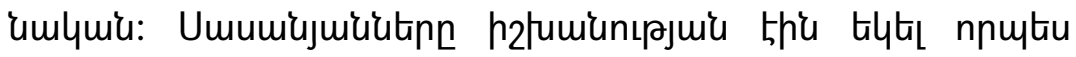

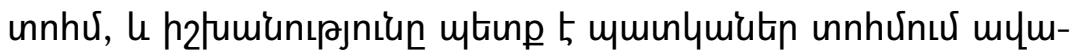

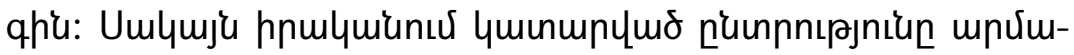

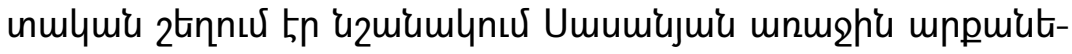

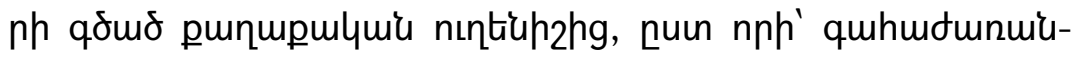

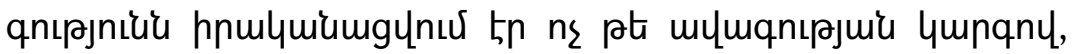

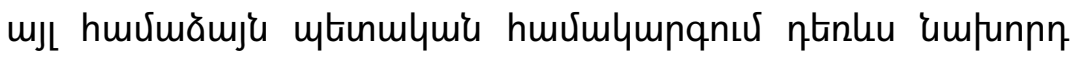

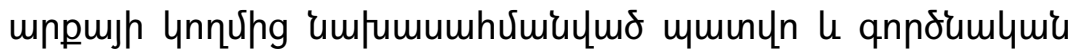

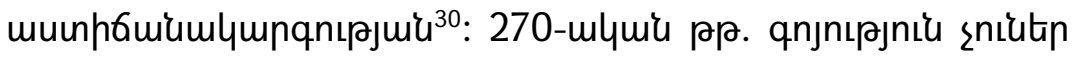

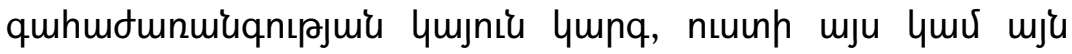

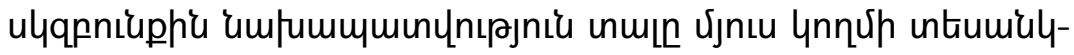

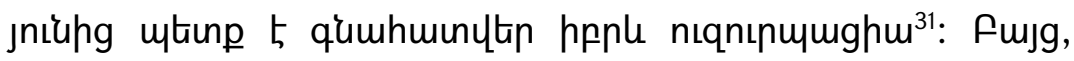

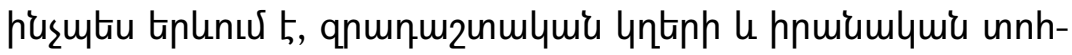

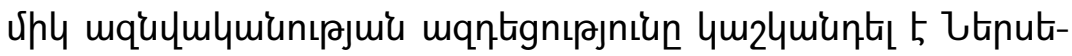

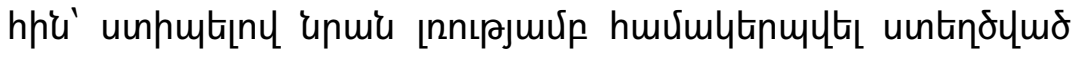

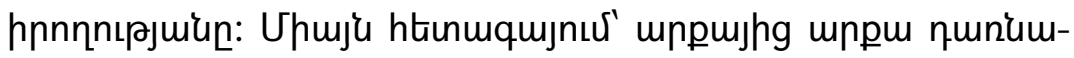

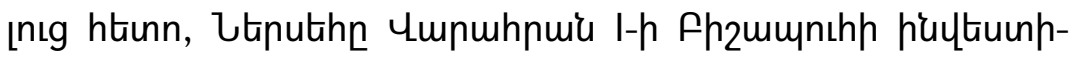

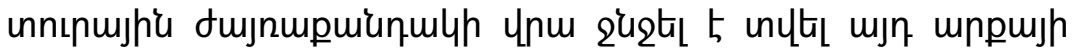

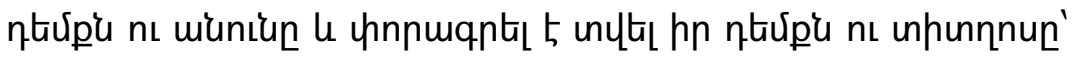

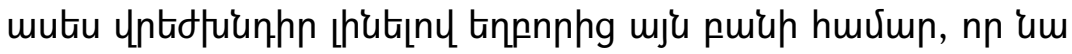

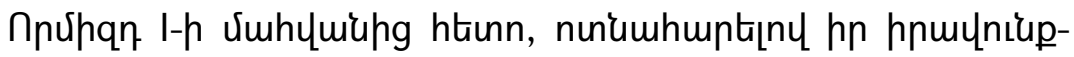

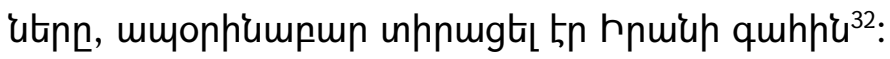

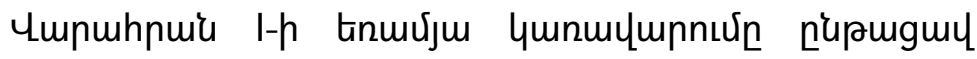

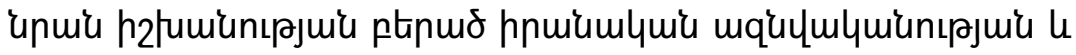

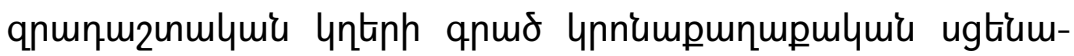

\footnotetext{
${ }^{30} \mathrm{Uth}$ hpjuiq U., \{2u. u2hu., tq 102-112:

31 Луконин В. Варахран II и Нарсе, стр. 50.

32 Луконин В. \{2૫. u2łu., tq 51:
} 


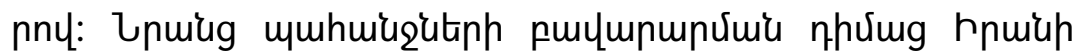

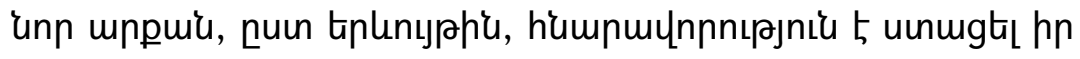

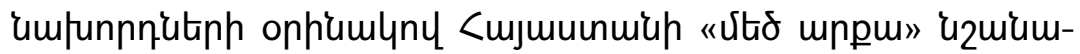

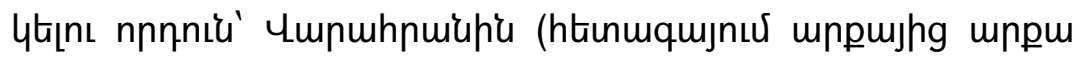

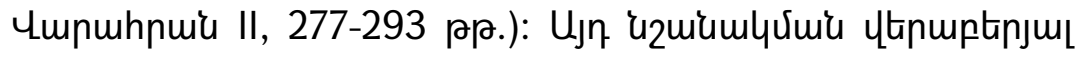

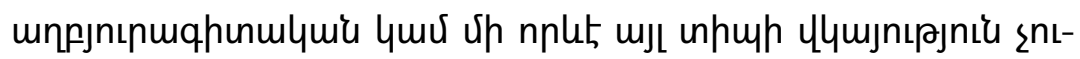
utüp: Umlymju mju plunuर tn up lnnर्uhg unp mppujh qu-

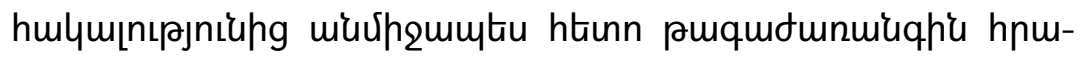

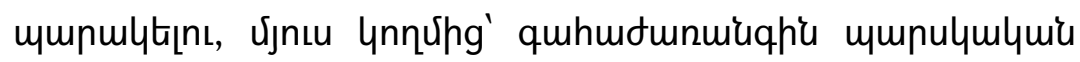

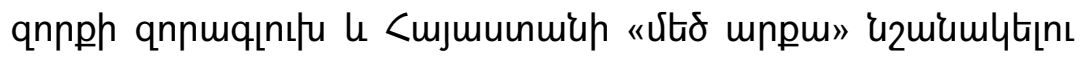

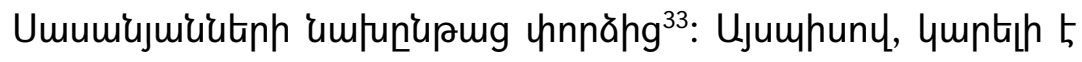

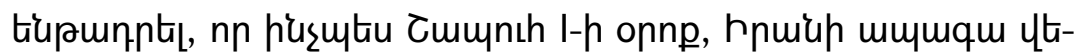

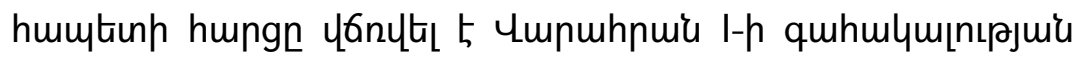

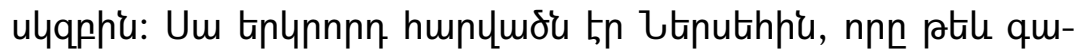

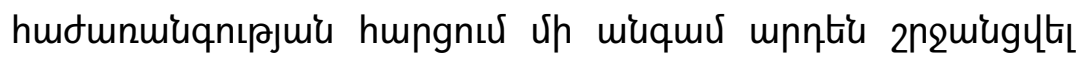

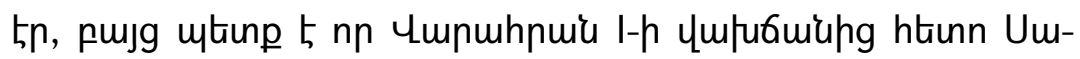

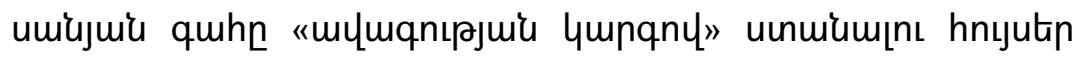

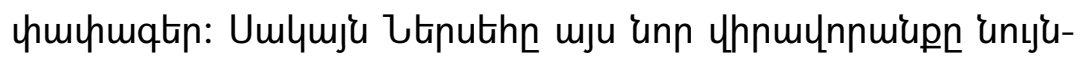

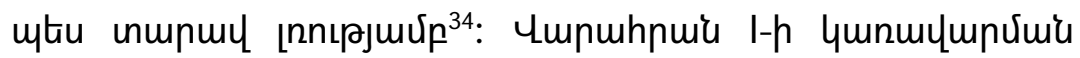

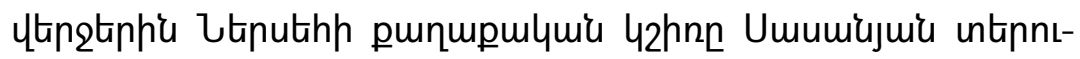

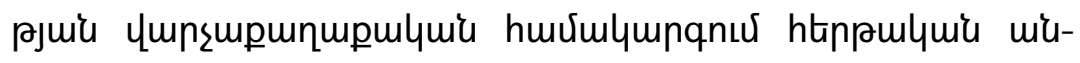

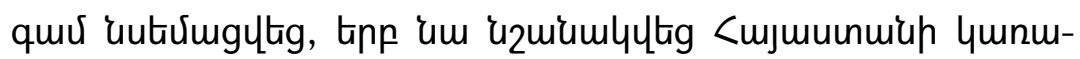
yunhs:

Tuunvimqhunnıرuiu vita ltiputhh uju unn izmiuml-

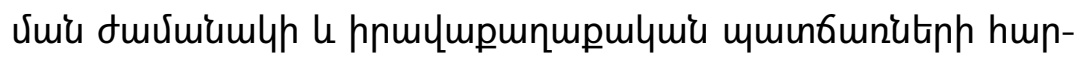

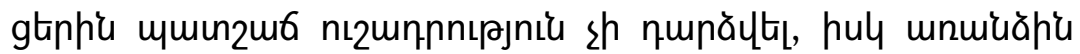

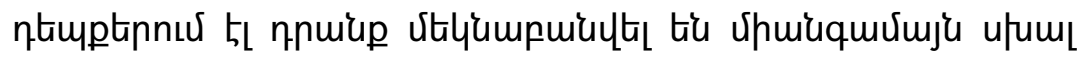

\footnotetext{
${ }^{33}$ Utılhpjui U., \{́24. u2hu., to 102-133:

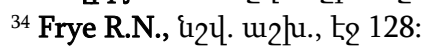




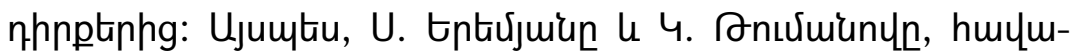

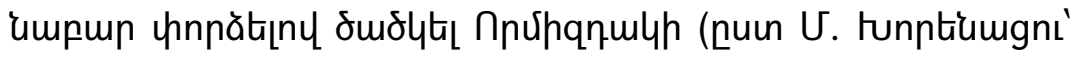

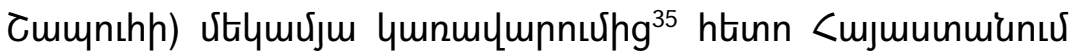

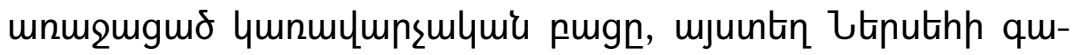

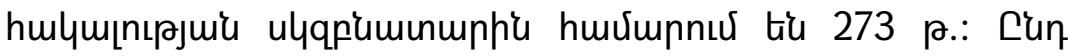

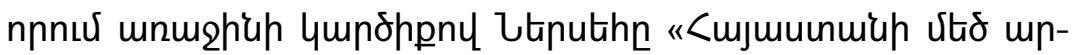

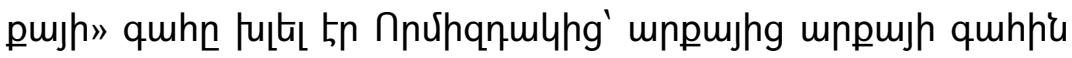

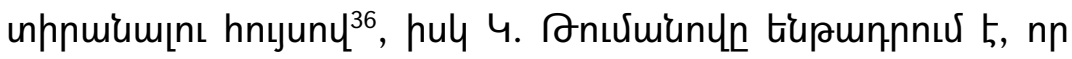

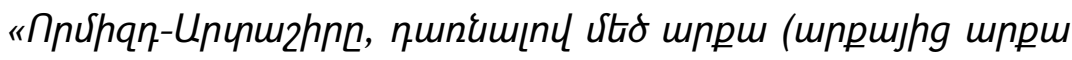

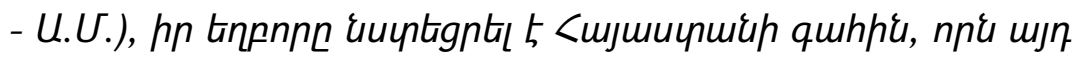

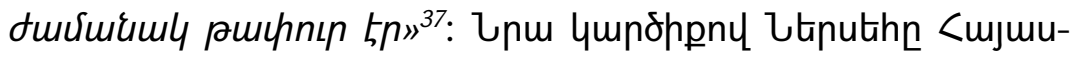

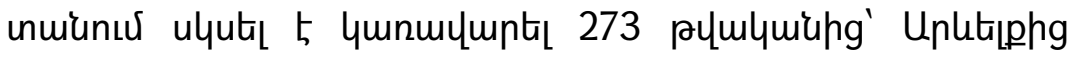

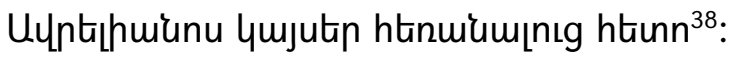

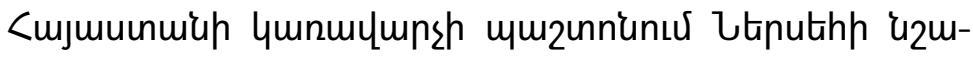

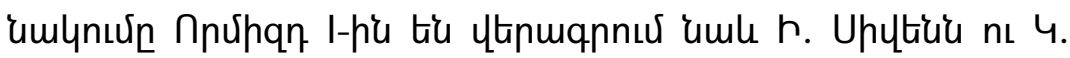

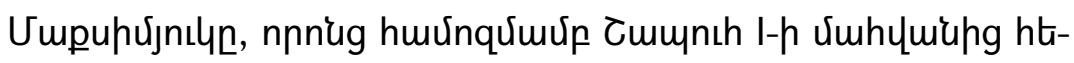

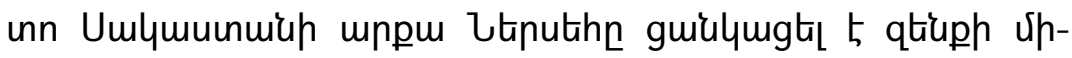

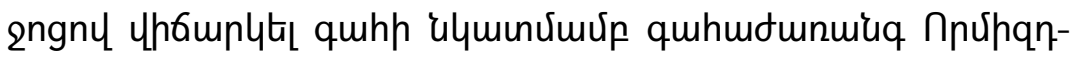

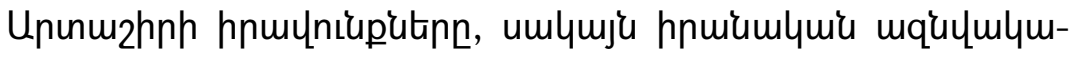

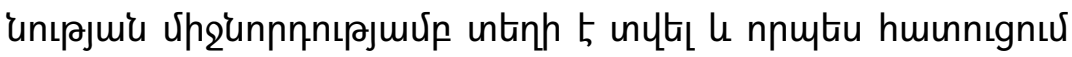

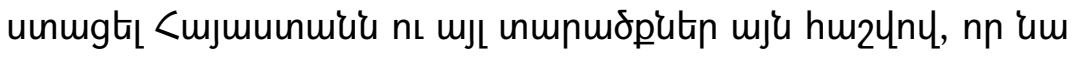

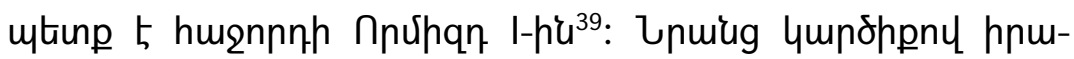

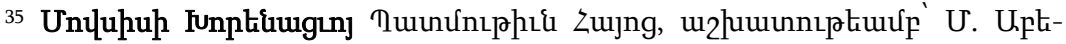

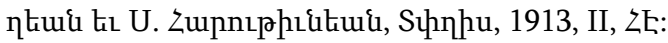

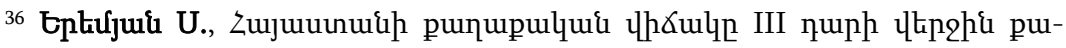

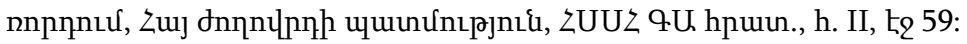

37 Toumanoff C., The third century Armenian Arshacids. A Cronlogical commentary. Revue des etudes Arméniennes. 1969, N VI, p. 257.

38 七nıjl untinnıu:

${ }^{39}$ Syvänne I. and Maksymiuk K., \{12૫. u2hu., Łq 109:
} 


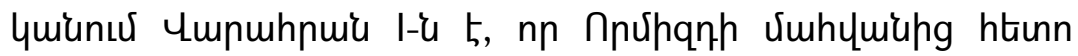

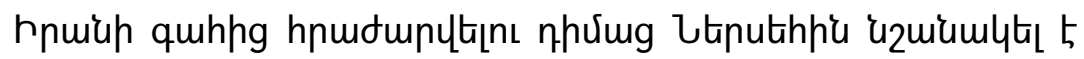
<mjuuunuiuh wnpmin:

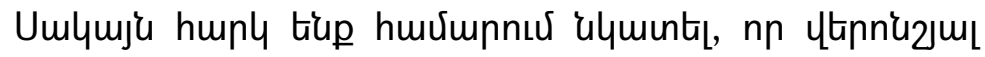

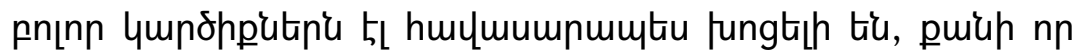

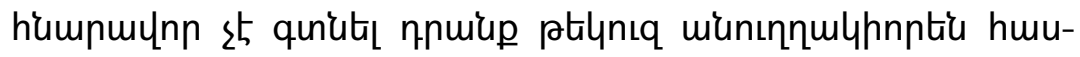

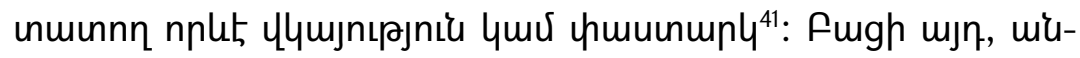

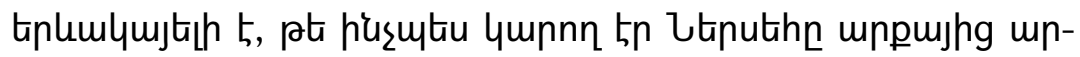

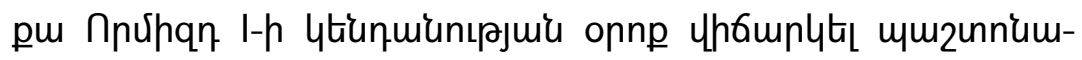

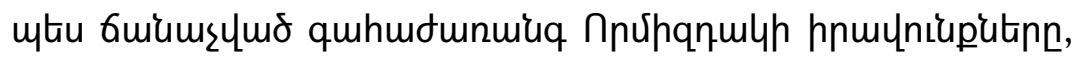

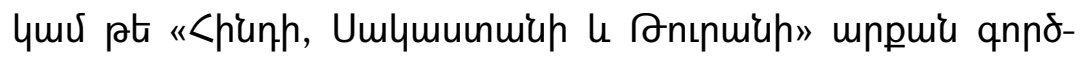

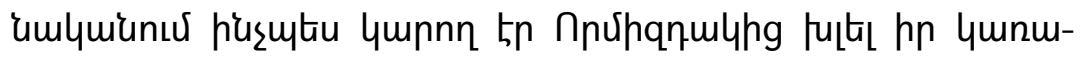

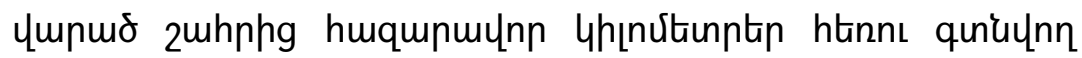

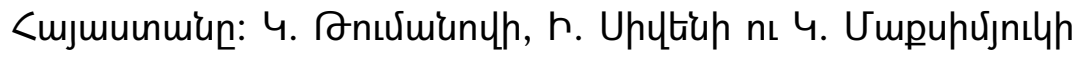

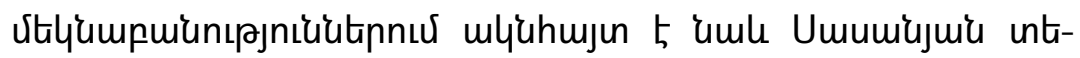

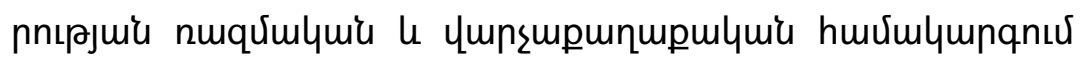

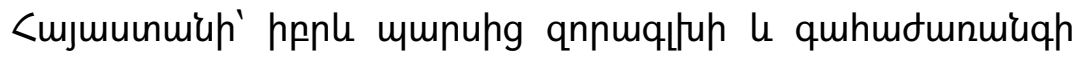

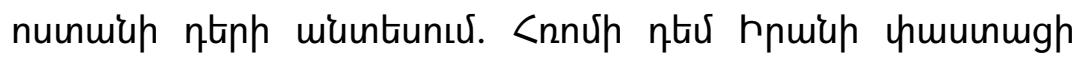

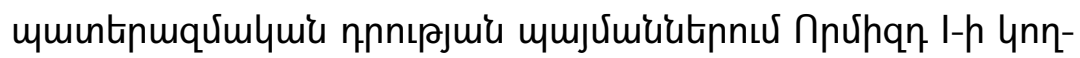

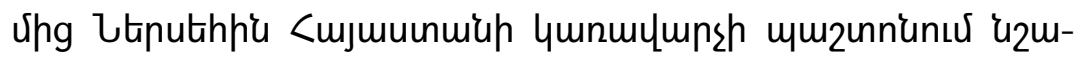

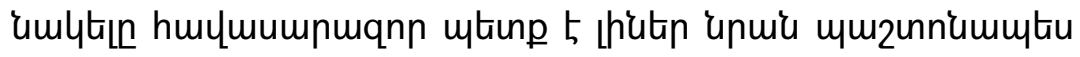

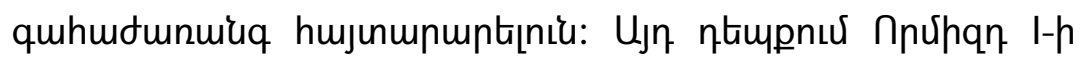

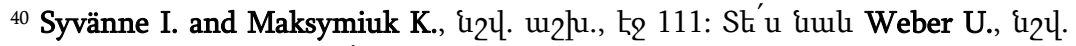
u2hu., to 153-160; ' unujup' Narseh, EIr, online edition, 2016.

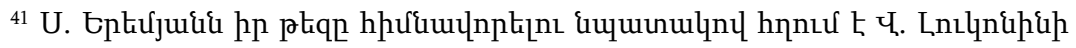

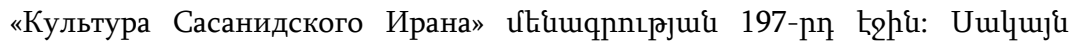

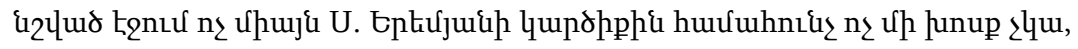

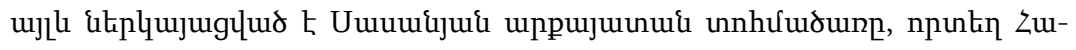

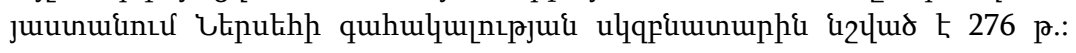
¿ưư. Луконин В. Варахра II и Нарсе. Стр. 52.
} 


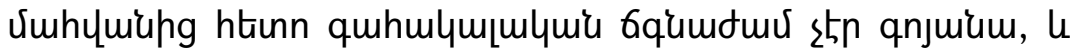

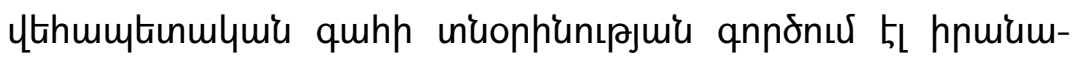

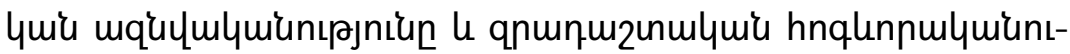

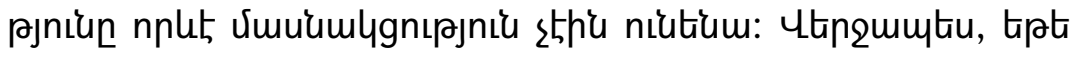

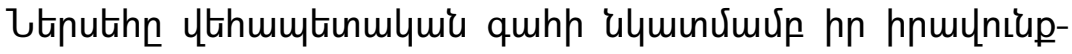

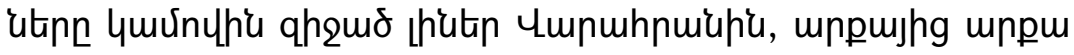

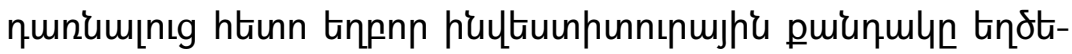
[nı unhp stn niutium:

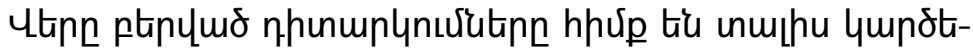

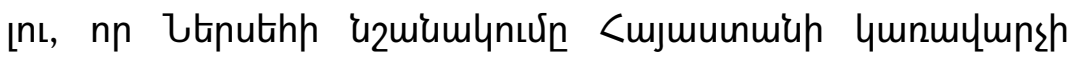

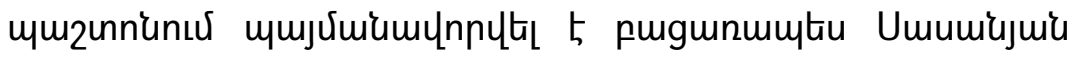

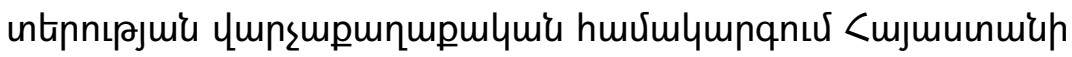

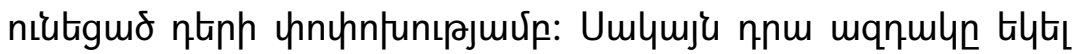

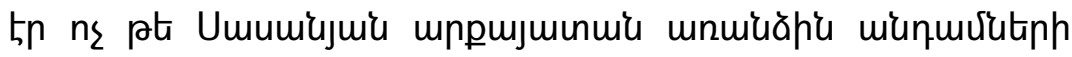

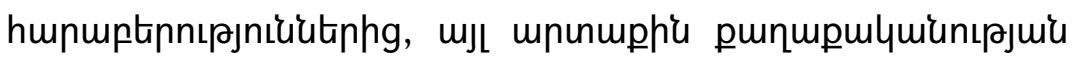
nınnunh:

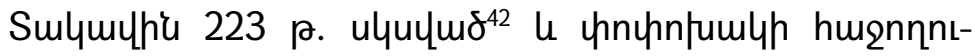

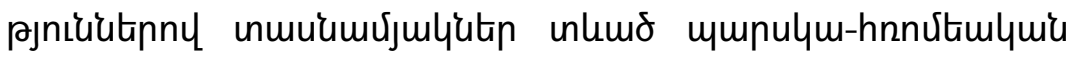

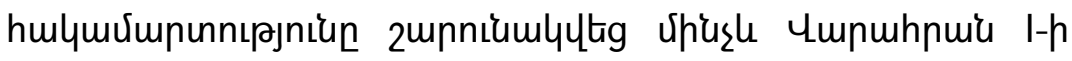

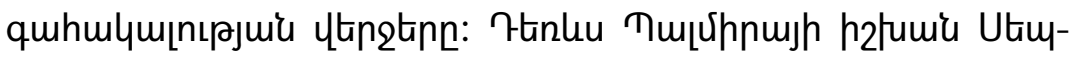

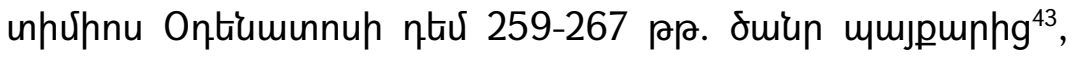

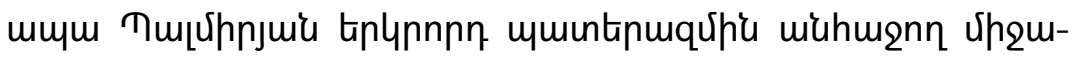

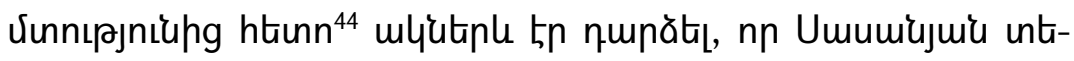

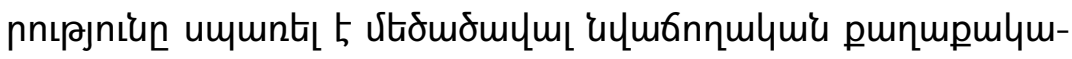

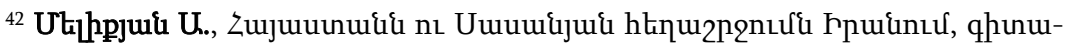

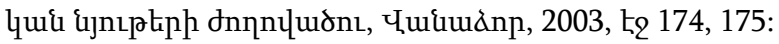

${ }^{43}$ Farrokh K., Shadows in the Desert: Ancient Persia at War, Oxford, 2007, pp.

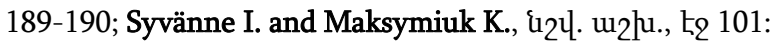

${ }^{44}$ Watson A., Aurelian and theThird Century, New York, 1999, p. 49; Syvänne I.

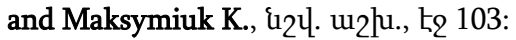




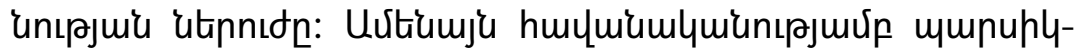

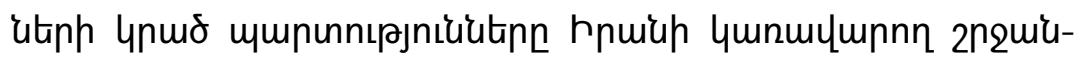

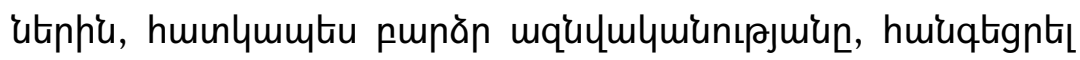

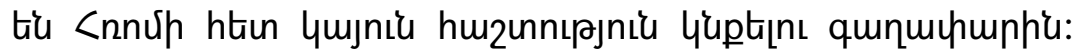

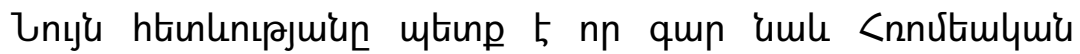

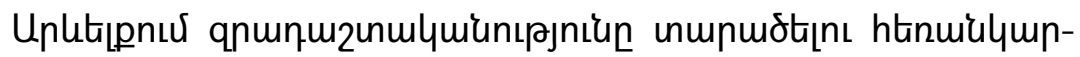
utphg hnsumfump qnunmizumulymi 4ntinn: Uju intumulyjnung sh puggununtu, nn <nnúp htion yujniu huzunnıpjuiu

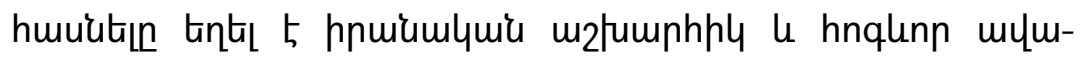

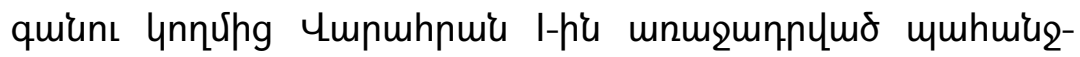

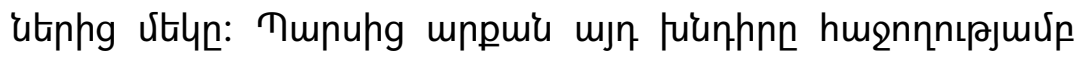

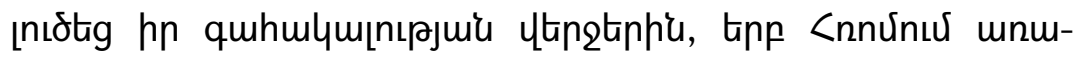

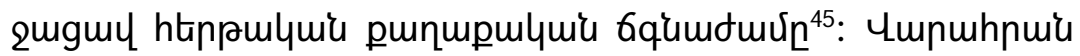

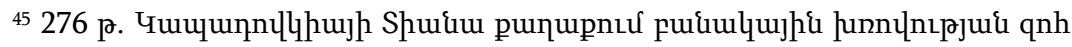

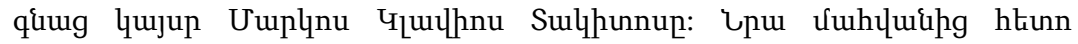

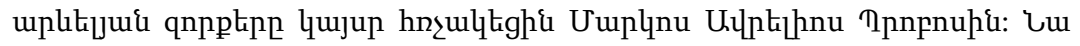

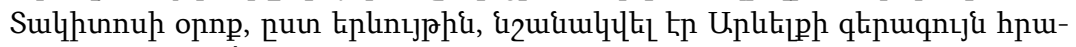
Uuquuunup (ut'́ u Грант М., Римские императоры, Москва, 1998, стр. 221),

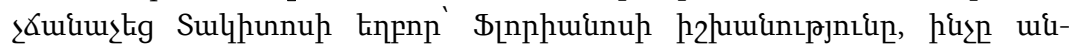

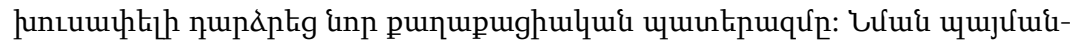

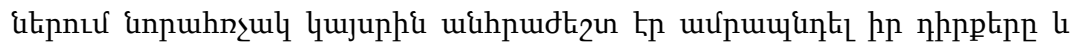

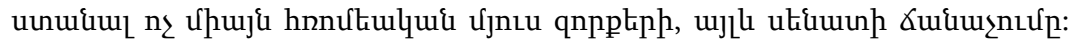

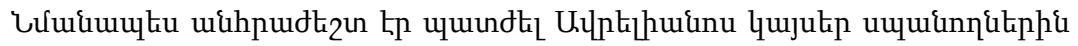

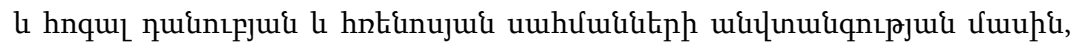

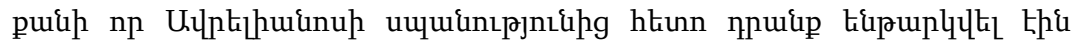

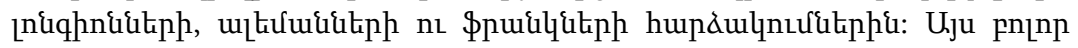

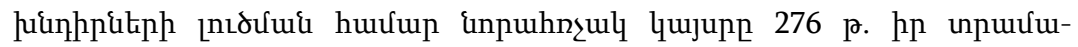

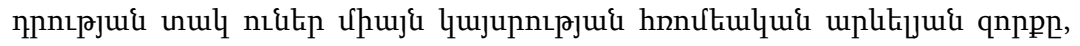

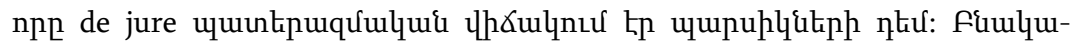

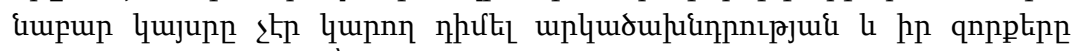

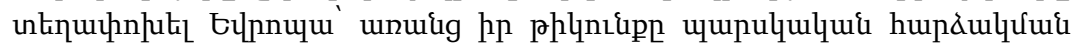

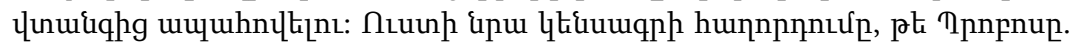

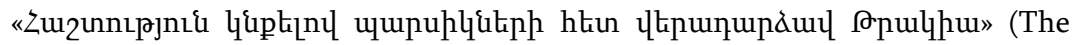




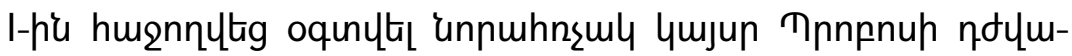

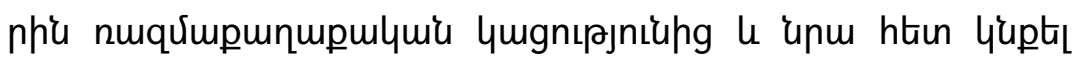

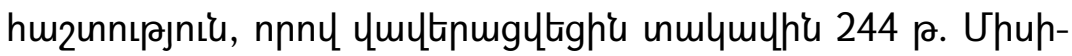

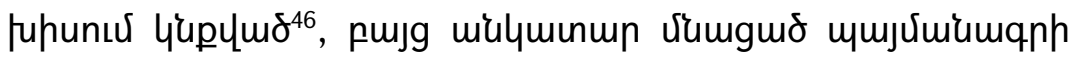

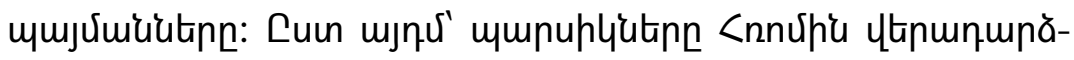

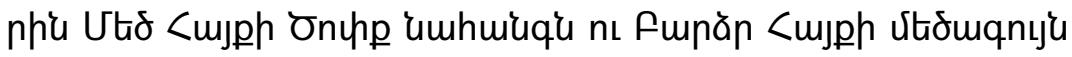

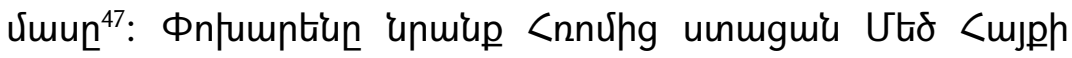

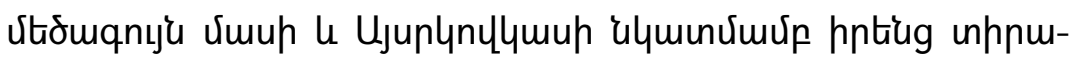

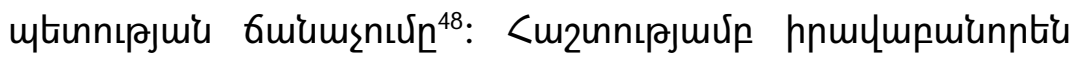

Scriptores Historiae Augustae, Vol. III, Cambridge, London, 1996, Probus, XVIII,

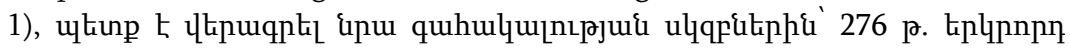
lturit:

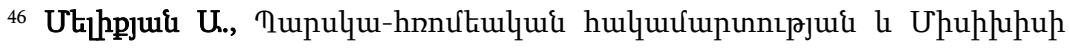

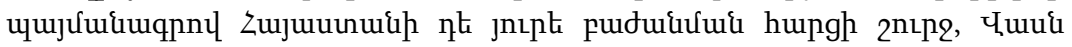

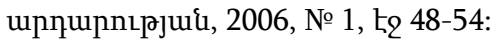

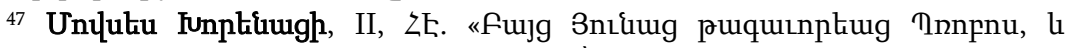
hum

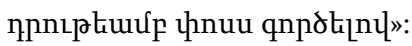

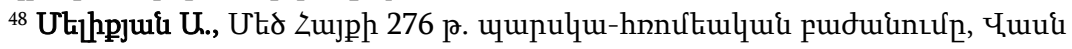

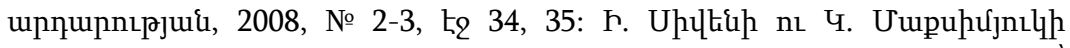

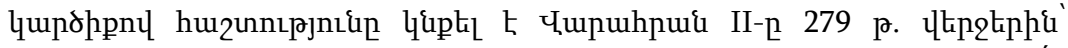

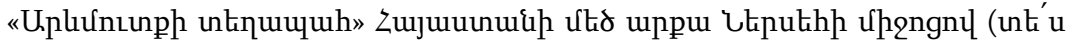

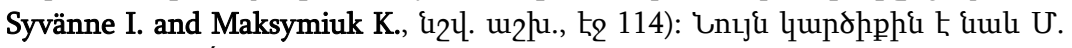
qpuiunn (unt'u Грант М., Римские императоры, стр. 222): U. Uup-

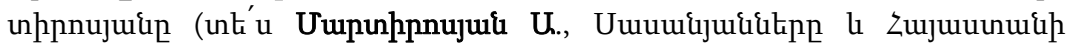

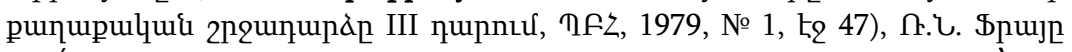
(unt' u Frye R., The History of Ancient Iran, München, 1985, p. 305. 'unujup' The Political History of Iran Under the Sasanians, p. 128), م. ?upjujhi (un' u Daryaee T., Sasanian Persia: The Rise and Fall of an Empire, London-New York, 2009, p. 12), F. Үhquuuu nı E. Ч.huptenp (unt'u Dignas B. and Winter E., Rome and Persia in Late Aniquity: Neigbours and Rivals, Cambridge, 2007) lu ujıp

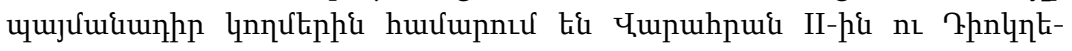
unpuinuhi: 


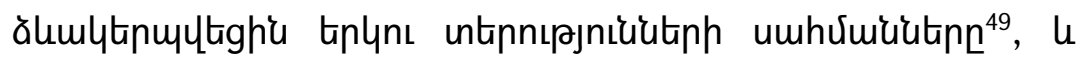

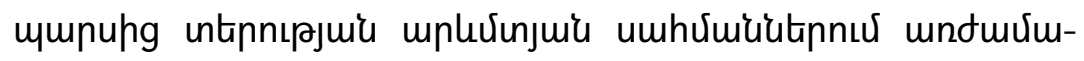

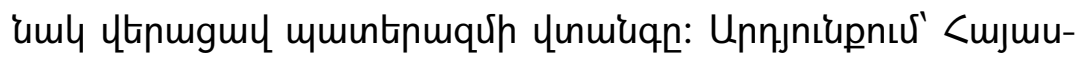

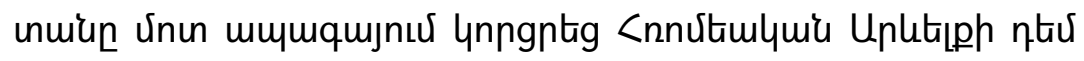

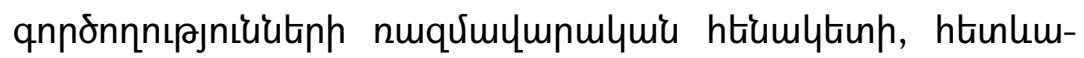

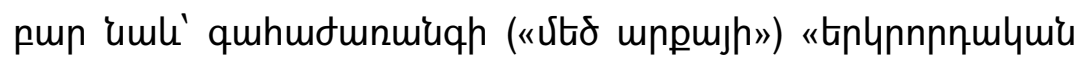

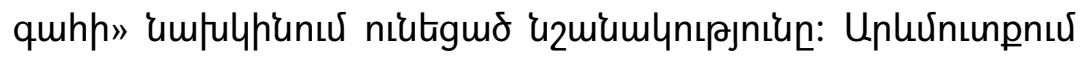

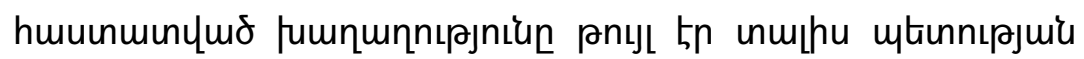

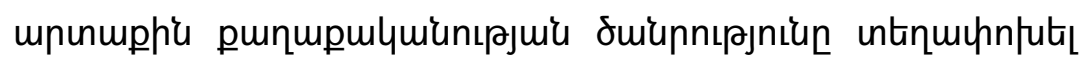

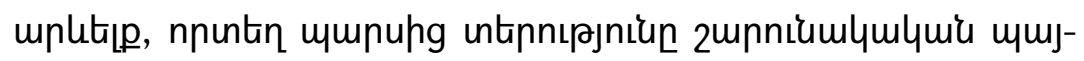

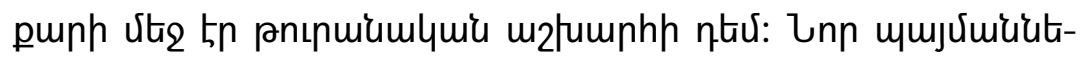

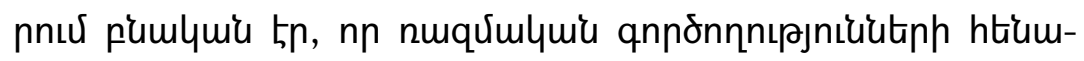

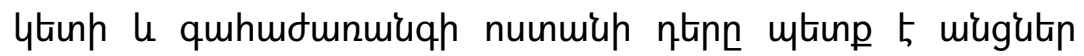

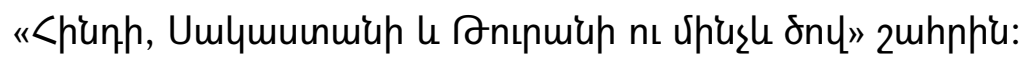

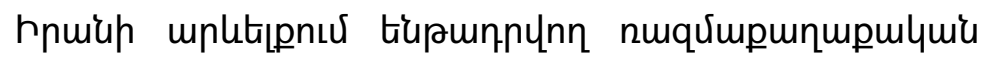

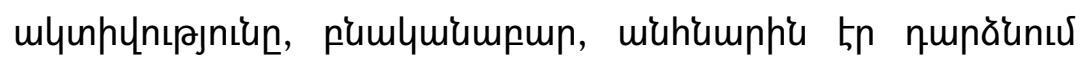

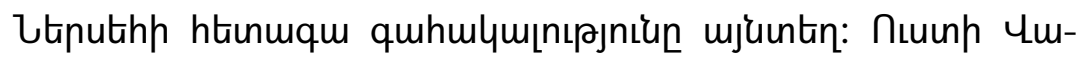

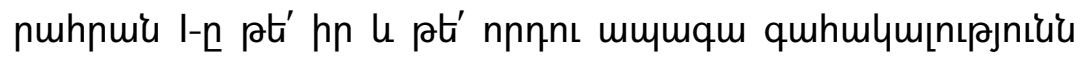

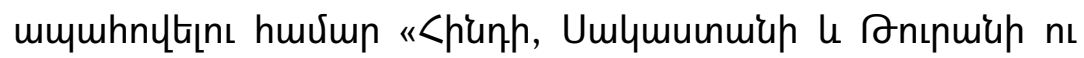

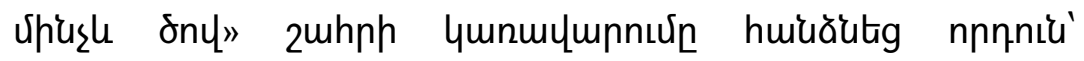

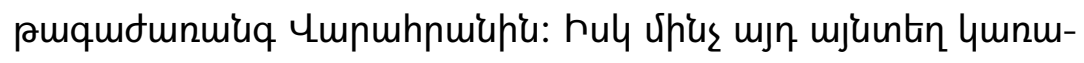
ympnn Utinutihn izmiumlyltig <mjununmiah ymnmumnsh щuzunnunเu:

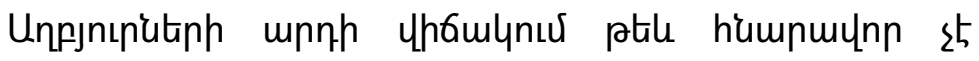

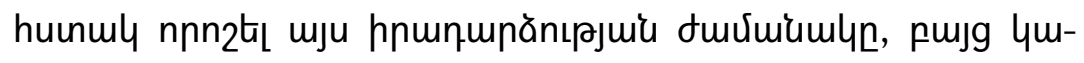

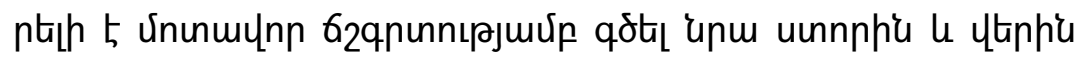

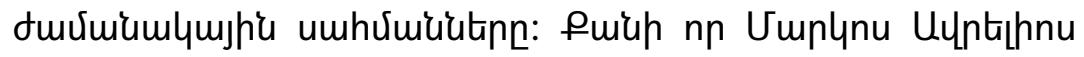

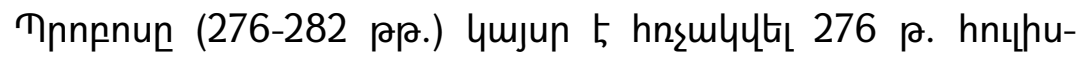

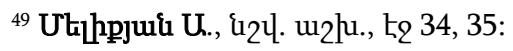




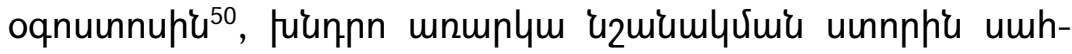

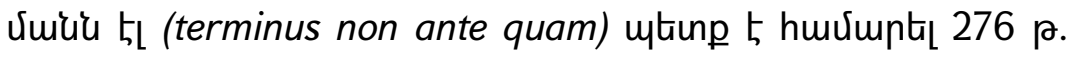
hnцhup ytingtinn ymu oqnuunnup ulqqütinn:

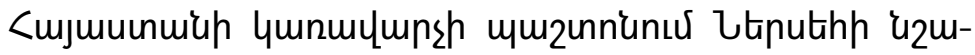

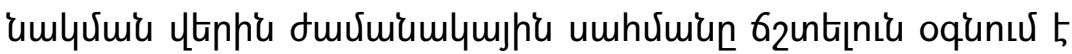

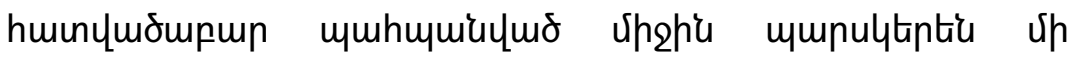

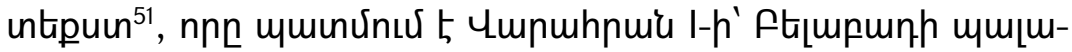

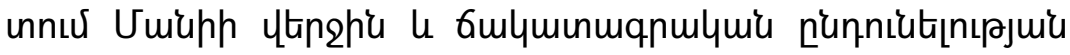

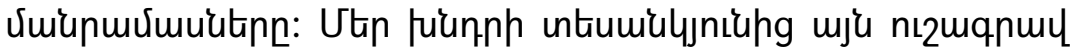

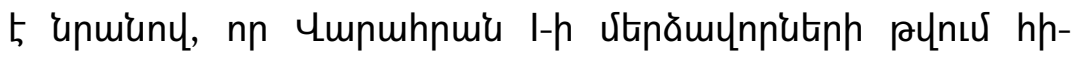

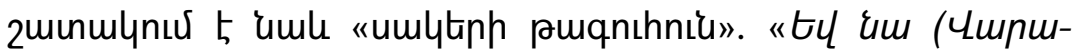

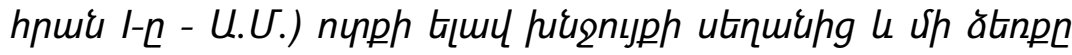

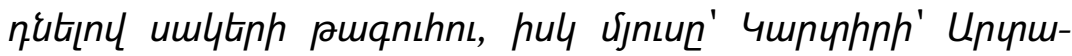

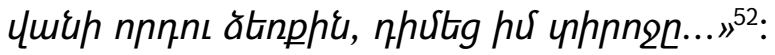

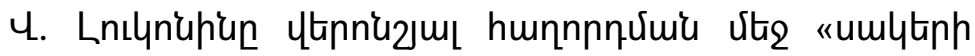

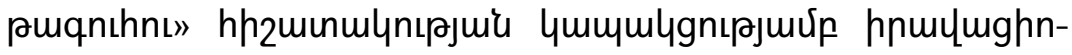

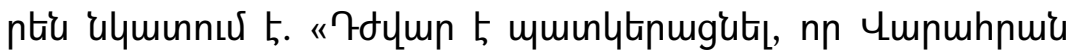

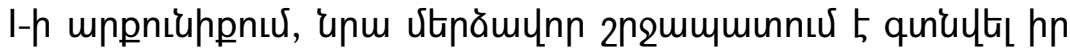

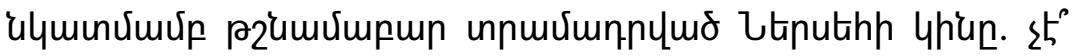

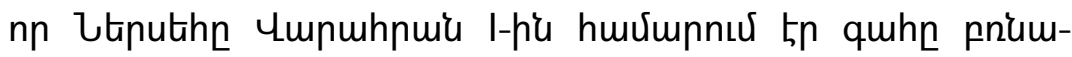

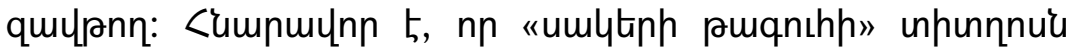

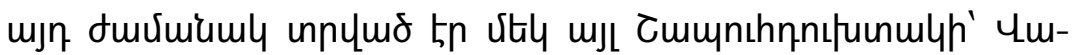

\footnotetext{
50 Властелины Рима: Биографии римских императоров от Адриана до Диоклетиана, перев. Кондратьев С.П., Москва, 2001, стр. 276, прим. 1410.

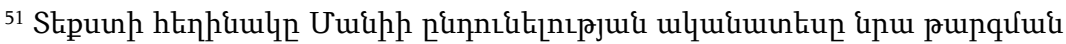

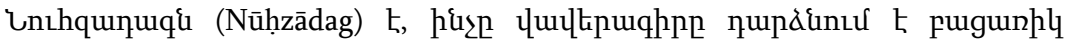
luunuhtiß (Sundermann W., Mani, EIr, 20 July 2009).

52 Henning W., Mani’s Last Journey, BSOAS, № 10, 1942, pp. 949-952; ¿nıjuh' Selected Papers I-II, Leiden, 1977, II, pp. 89-92; Виденгрен Г., Мани и манихейство, стр. 66.
} 


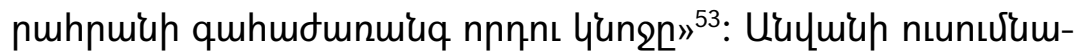

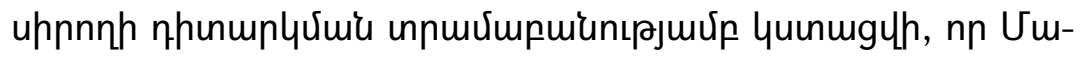

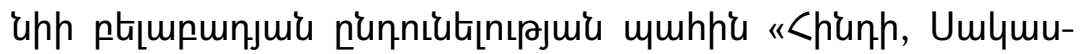

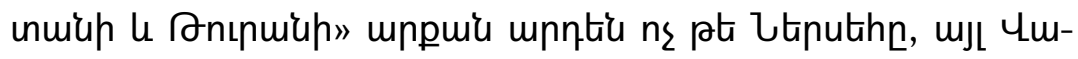

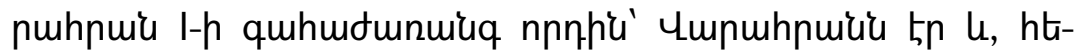

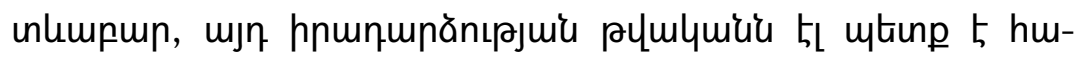

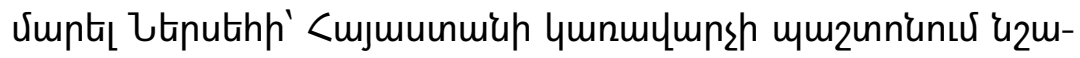

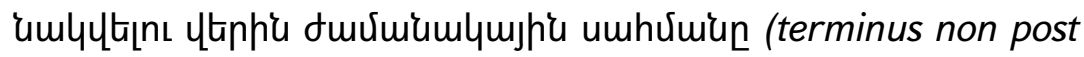
quam):

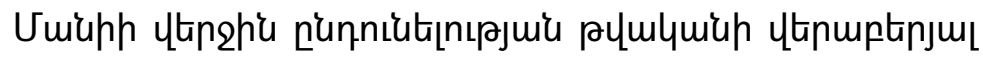

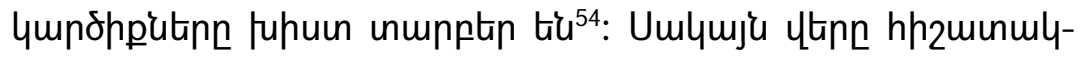

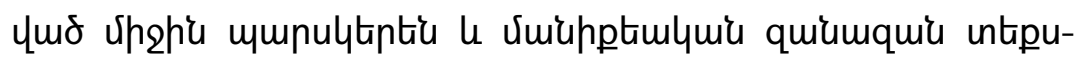

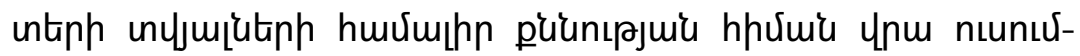

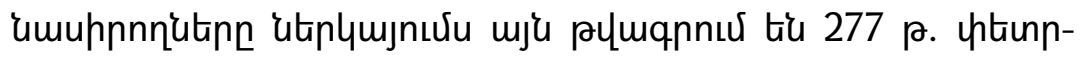

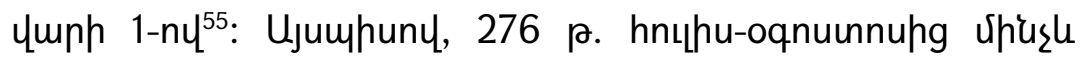

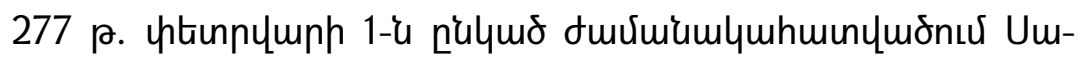

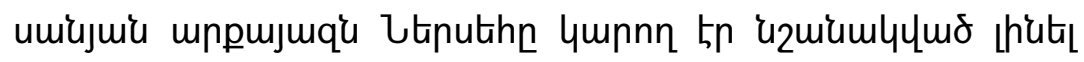

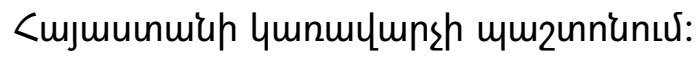

\footnotetext{
53 Луконин В. Варахран II и Нарсе. Стр. 51, 52.

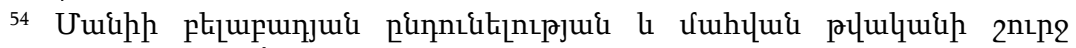
luupluudđitinn unt'u usmussen J., Xuâstvânift. Studies in Manichaeism. Kopenhagen, 1965, p. 10; Klima O., Manis Zeit und Leben. Prag, 1962, S. 381-382; Klima O., Zwei Stellen (17, 24 ff und 18, 6 ff) des manichaischen Psalters. PKL (Probleme der koptischen Literatur. Hrsg. vom Institut fur Byzantinistik der Martin-Luther-Universitat Halle-Wittenberg. Bearb., v. P. Nagel (Wissenschaftliche Beitrage der Martin-Luther-Universitat Halle-Wittenberg 1968/1). Halle (Saale), 1968, S. 121-123.

55 Taqizadeh S. H., The Early Sasanians. Some Chronological Points which Possibly Call for Revision. BSOAS, № 11, 1943-1946, p. 49 ff; Tardieu M., Le Manicheisme. Paris, 1981, p. 40; Skjærvø P.O., An Introduction to Manicheism, 2006, p. 27; Sundermann W., Mani, EIr, 20 July 2009; Хосроев А.Л., История Манихейство, Санкт-Петербург, 2007, стр. 107.
} 


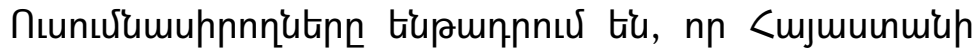

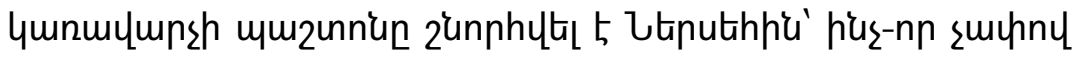

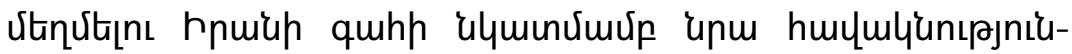
Uthn ${ }^{56}$ : Cuun mjnu

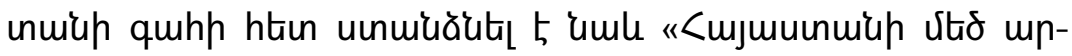

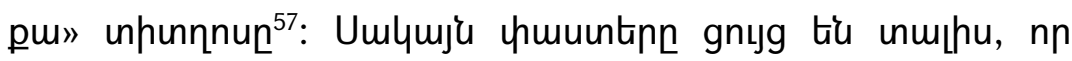

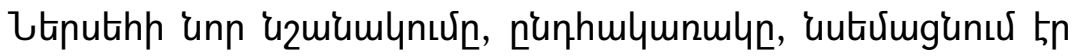

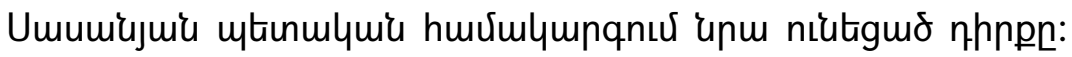

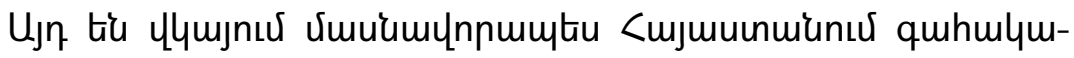

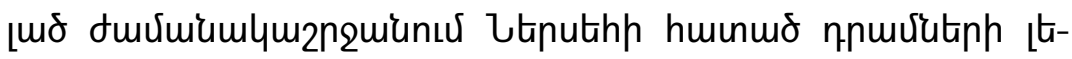

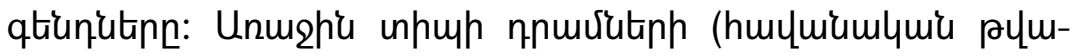

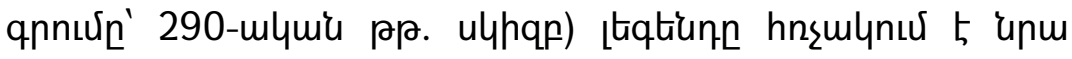

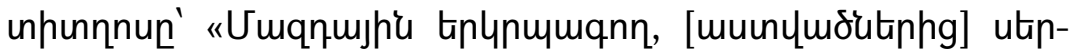

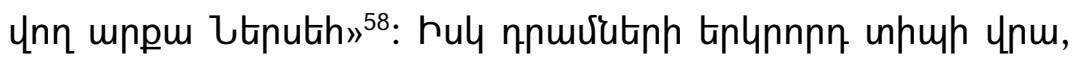

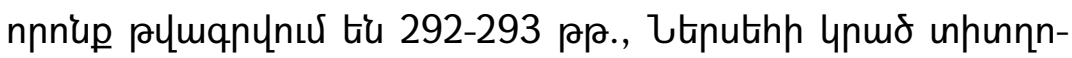

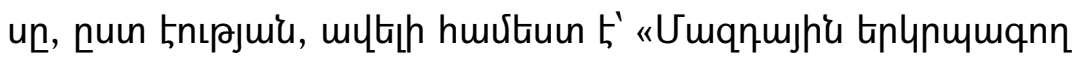

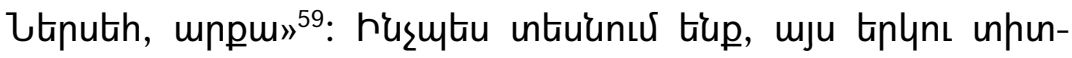

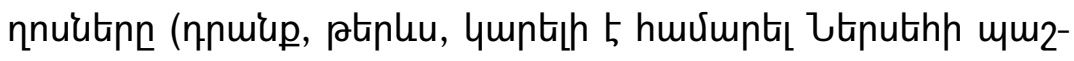

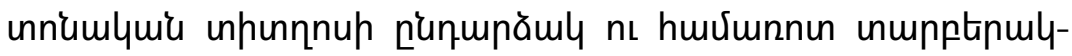

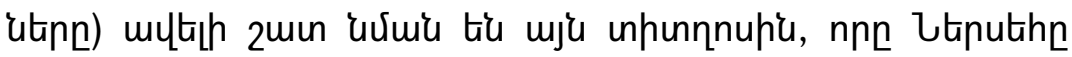

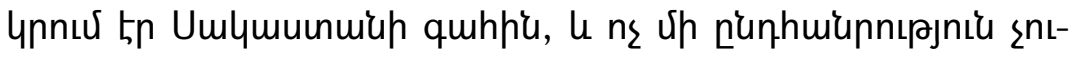

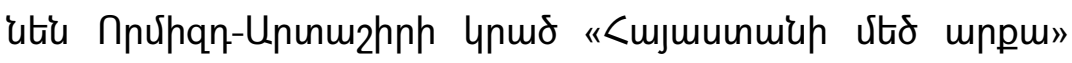

\footnotetext{
56 Луконин В., Варахран II и Нарсе, с. 52.

${ }^{57}$ Daryaee T., Sasanian Persia: The Rise and Fall of an Empire, pp. 10-11. Daryaee T., A Note on the 'Great King of Armenia' in: Bridging Times and Spaces: Papers in Ancient Near Eastern, Mediterranean and Armenian Studies Honouring Gregory E. Areshian on the occasion of his sixty-fifth birthday, Oxford, 2017, p. 85; Syvänne I. and Maksymiuk K., The Military History of the Third Century Iran, p. 111.
}

58 Луконин В. Варахран II и Нарсе. Стр. 57.

59 unıju untınıu: 


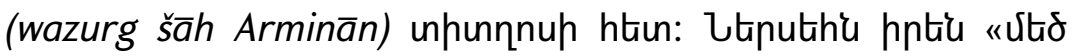

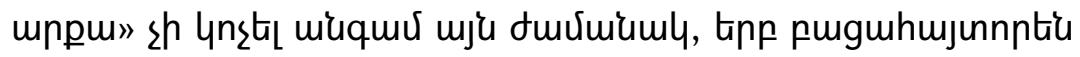

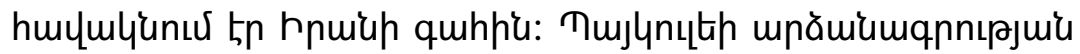

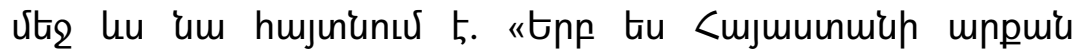
5 th.... ${ }^{60}$ :

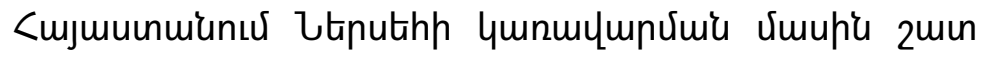

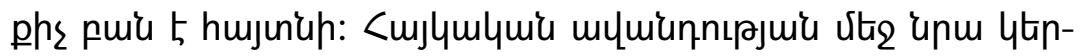

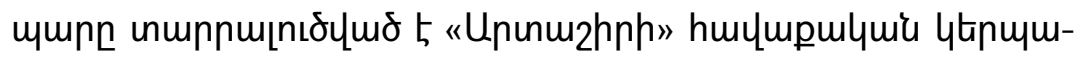

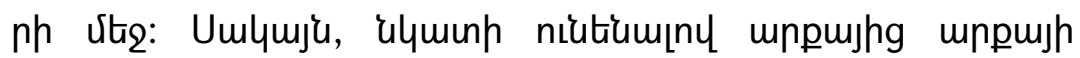

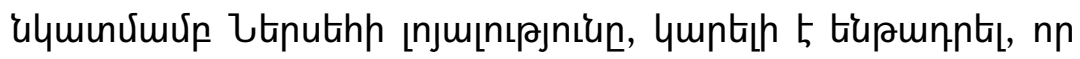

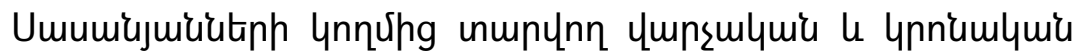

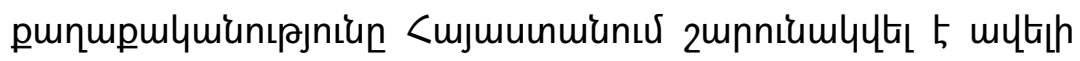

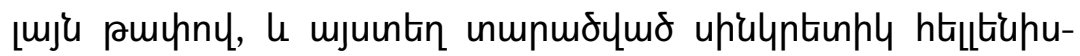

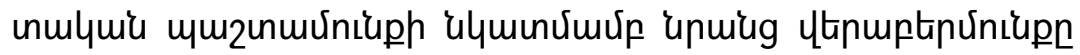

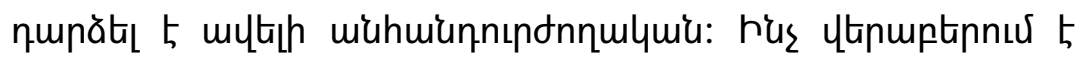

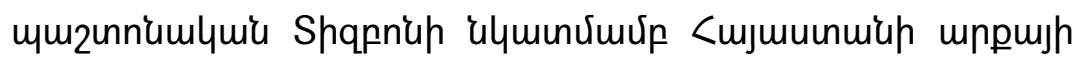

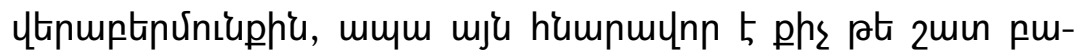

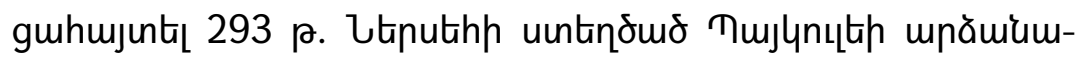

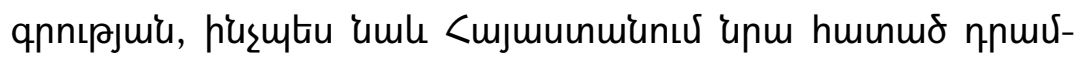

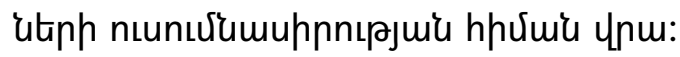

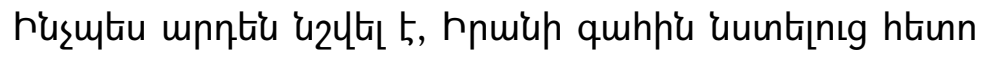

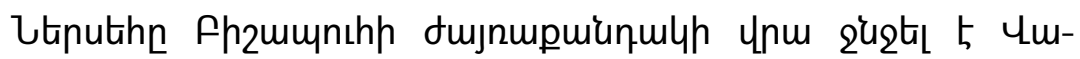

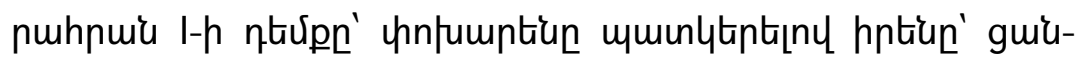

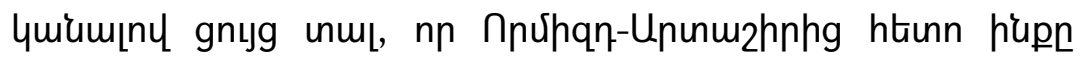

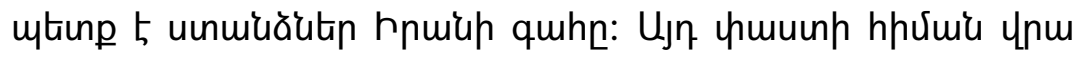

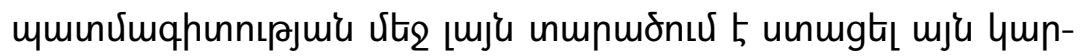

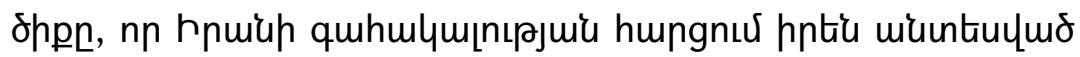

${ }^{60}$ Humbach H. and Skjærvø P.O., The Sassanian Inscription of Paikuli [NPi], Part 3.1, Munich, 1983, § 3 . 


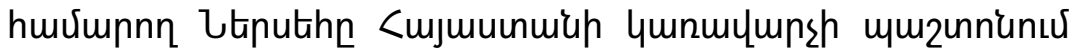

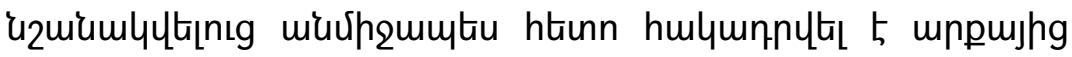

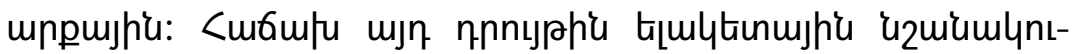

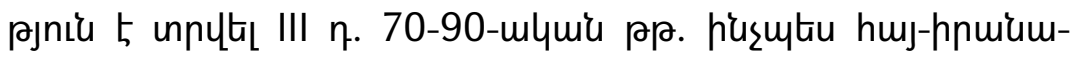

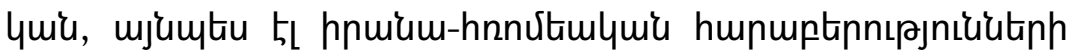

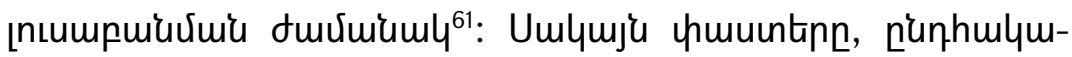

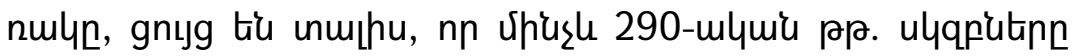

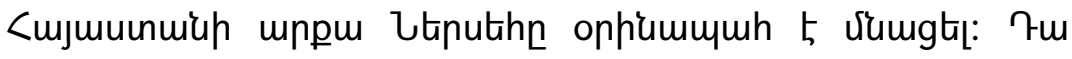

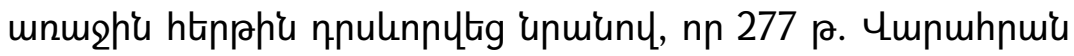

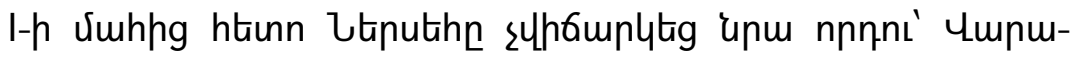

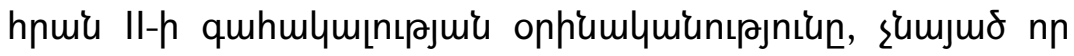

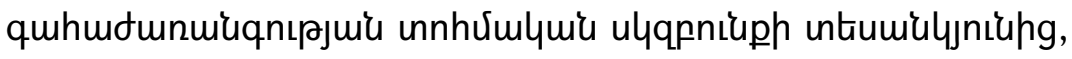

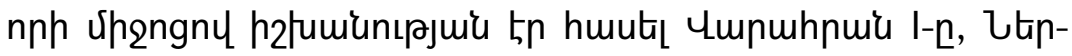

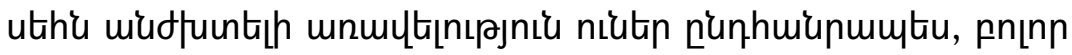

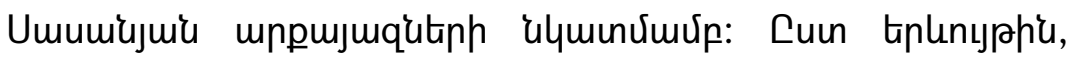

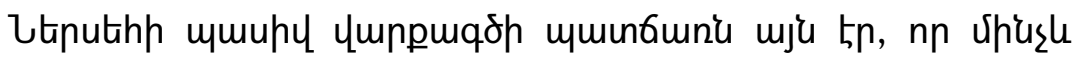

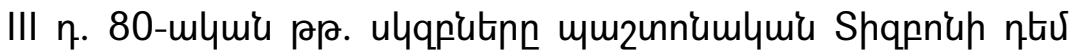

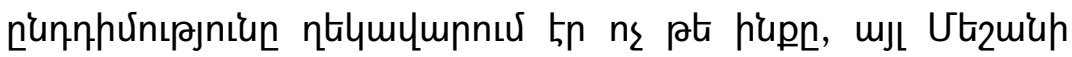

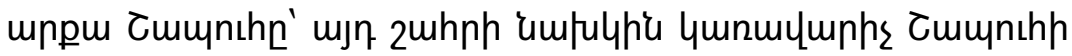

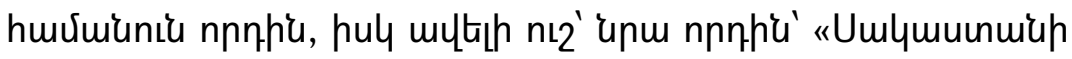

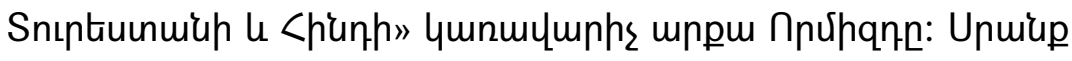

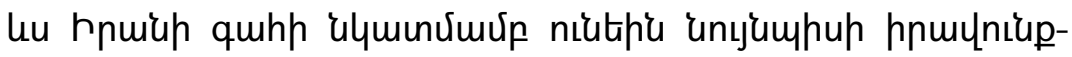

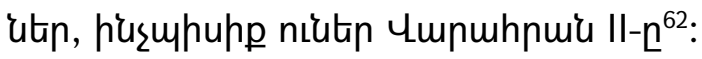

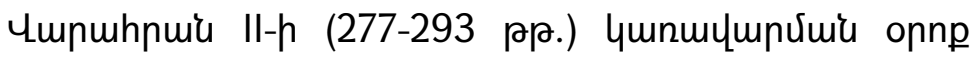

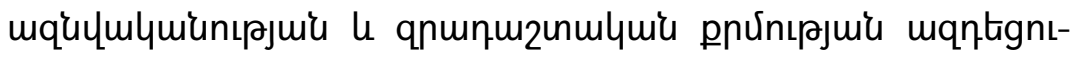

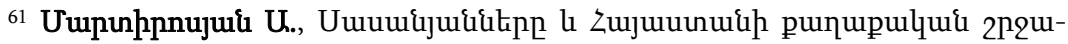

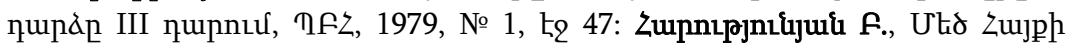

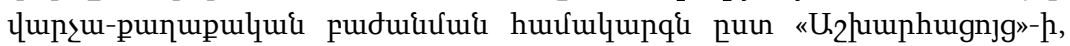
Epluwa, 2001, to 211:

62 Луконин В. Иран в III веке. Стр. 60. 


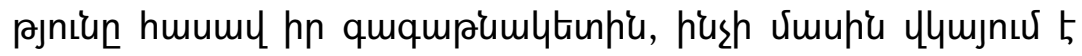

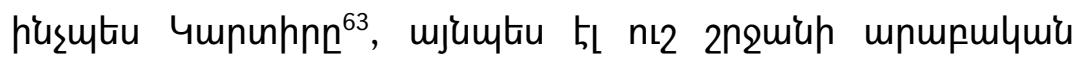

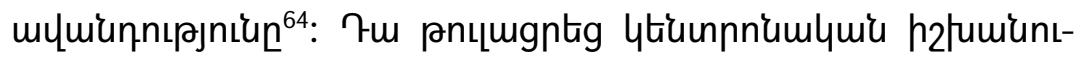

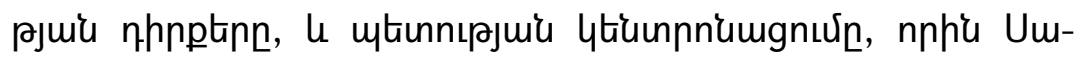

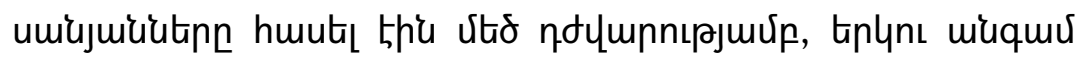

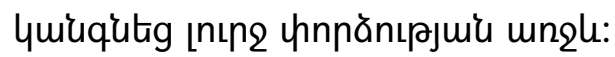

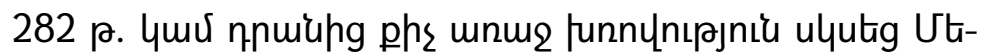

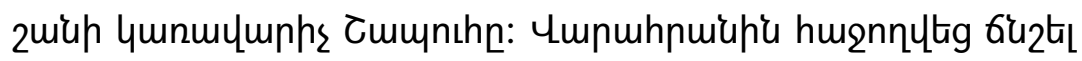

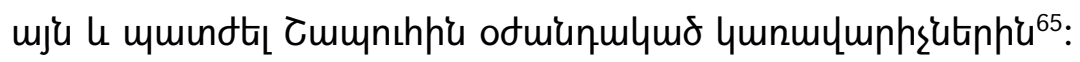

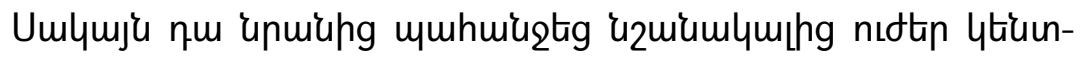

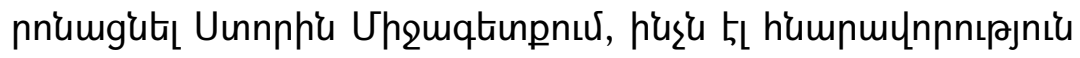

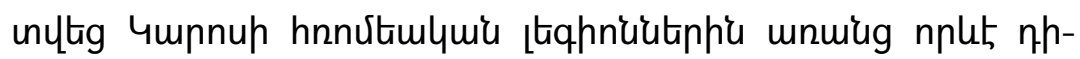

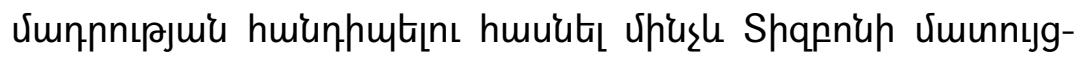

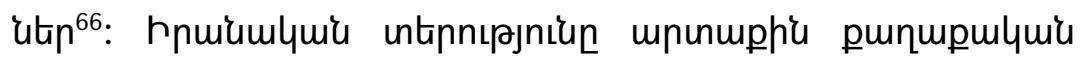

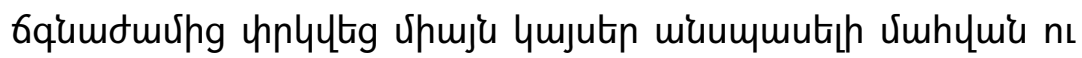

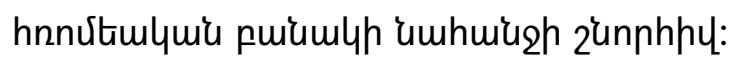

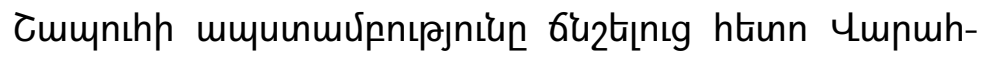

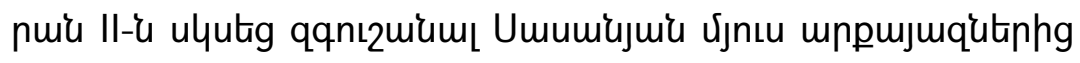

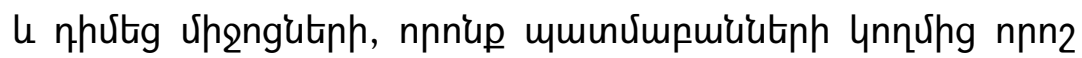

${ }^{63}$ Kerdir's Naqsh-e Rajab inscription, 13. St' u Sprengling M., Third Century Iran..., pp. 37-69; MacKenzie D.N., Kerdir's Inscription (synoptic text in transliteration, transcription, translation and commentary), in G. Herrmann, D.N. Mackenzie and R. Howell, The Sasanian Reliefs at Naqsh-i Rustam, Naqsh-i Rustam 6. The Triumph of Shapur I (together with an account of the representations of Kerdir), Description and Commentary, Kerdir's Inscription (synoptic text in transliteration, transcription, translation and commentary), Iranische Denkmaler 13, enthaltend Reihe II, Iranische Felsreliefs I, Berlin, 1989, pp. 35-72. Луконин В., Картир и Мани, ВДИ, 1966, № 3, стр. 75.

${ }^{64}$ The History of al-Tabari, Vol. V, p. 46.

65 Луконин В. Иран в ІІІ веке. Стр. 60.

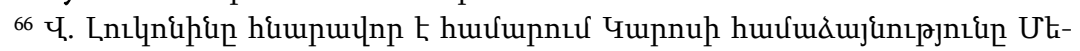
2u\{h uppujh htin (Луконин В. Иран в III веке. Стр. 60): 


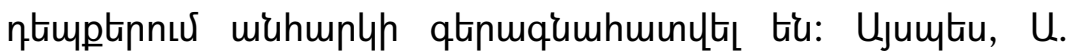

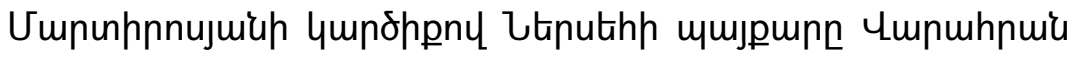

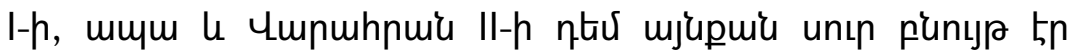

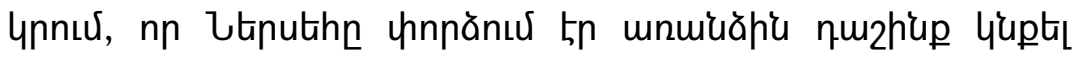

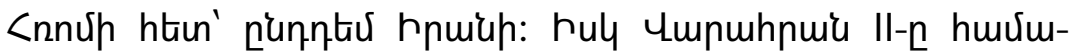

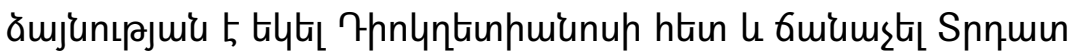

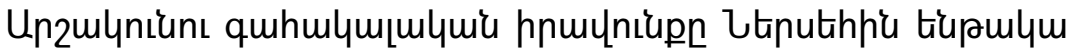

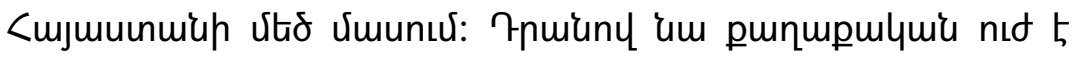

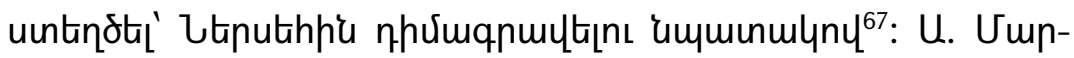

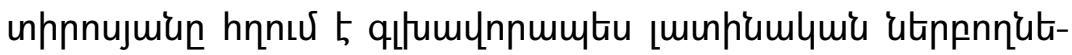

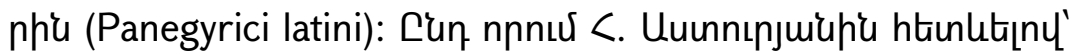

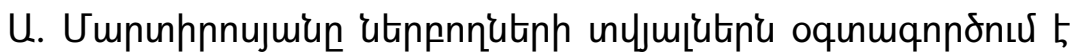

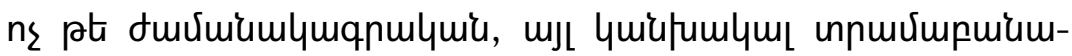

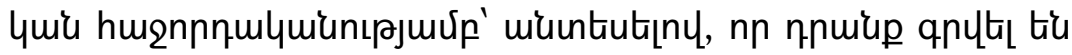

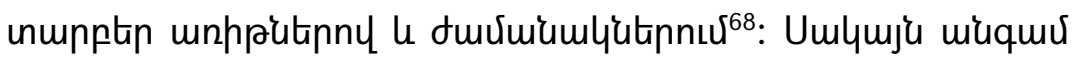

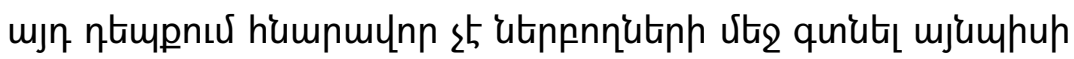

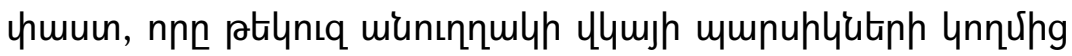

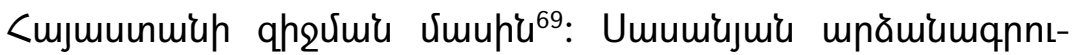

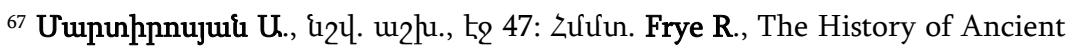
Iran, p. 305.

68 Латинские Панегирики. Перев. с лат. И.Ю. Шабага, ВДИ, 1996, № 3, стр. 210-214.

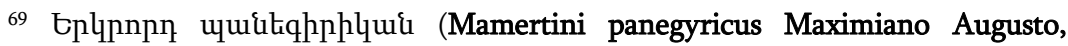

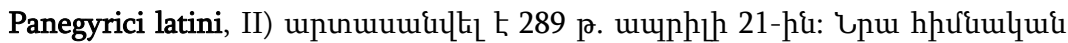

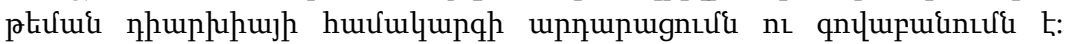

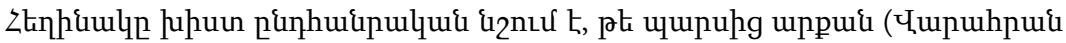

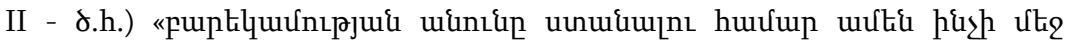

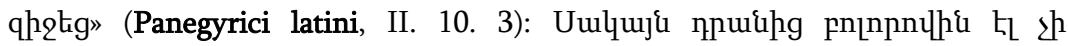

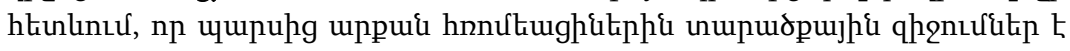

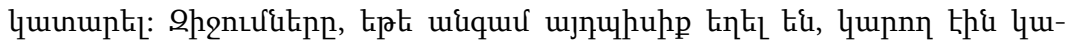

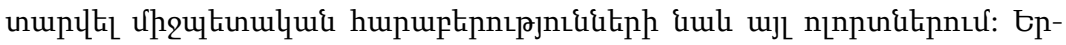

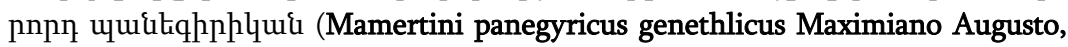




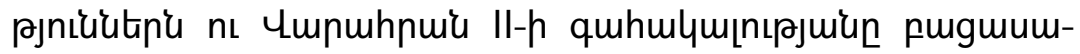

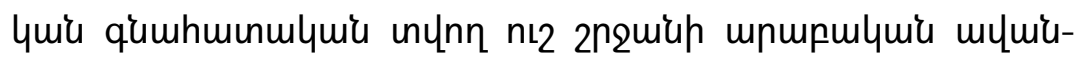

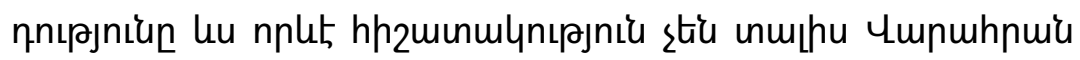

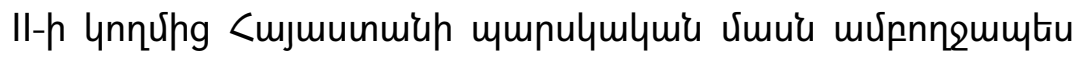

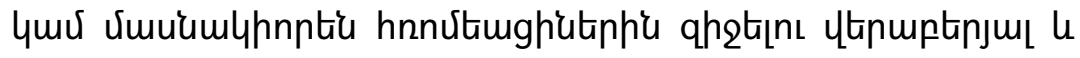

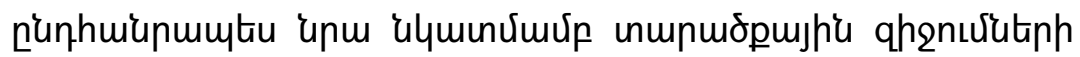

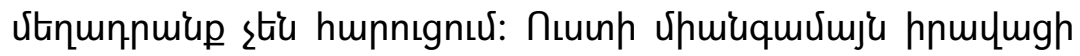

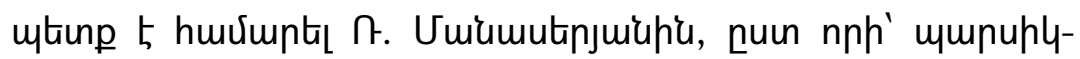

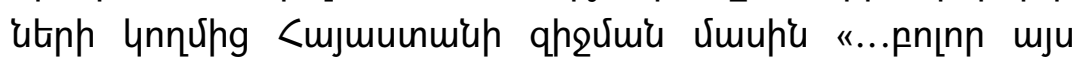

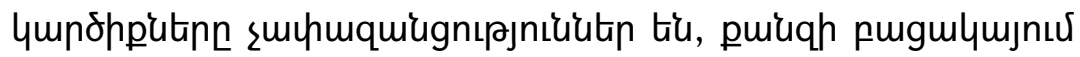

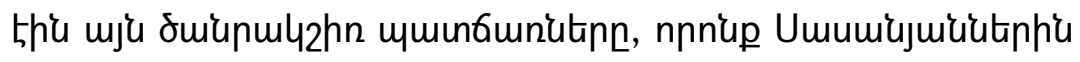

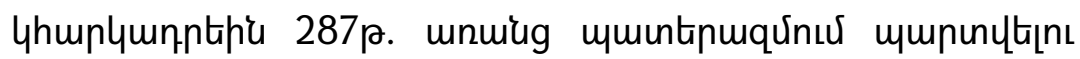

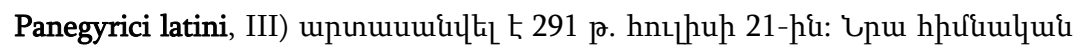

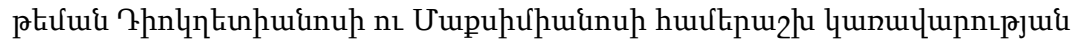

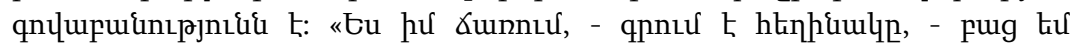

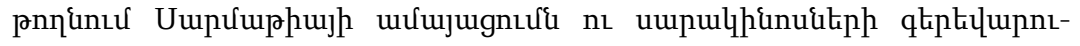

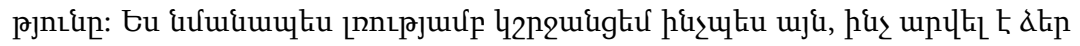

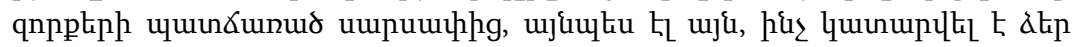

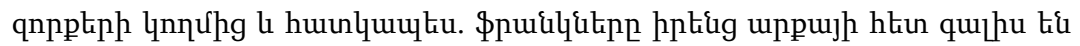

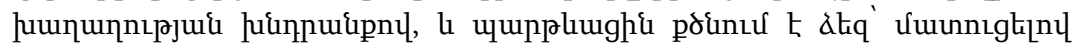

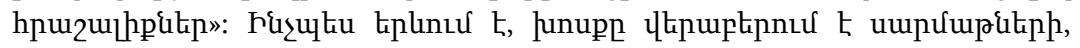

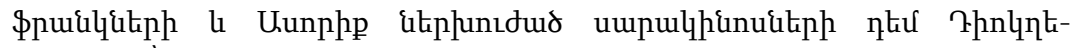

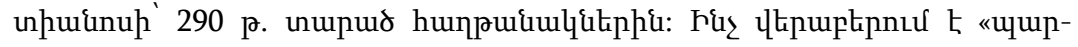

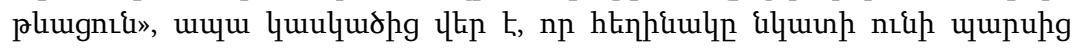

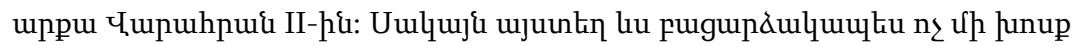

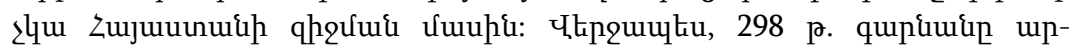
unuuuuulud hhiqtinnp đunnul (Eumenii pro instaurandis scholis oratio,

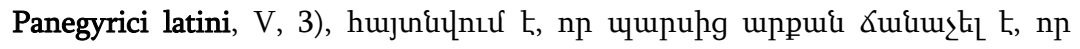

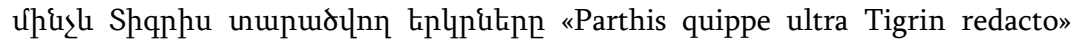

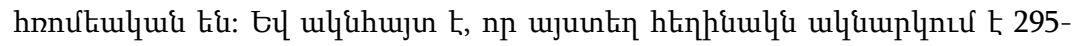

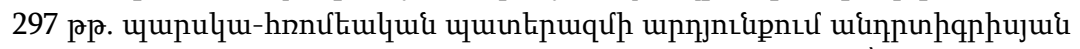

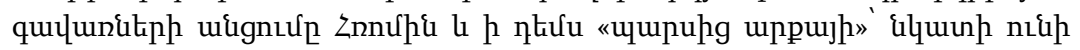

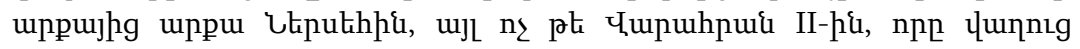
ltiquiul 2 th: 


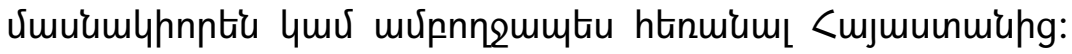

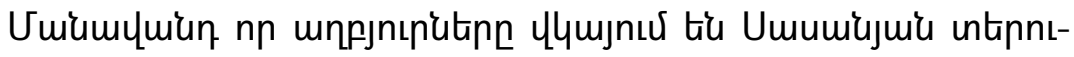

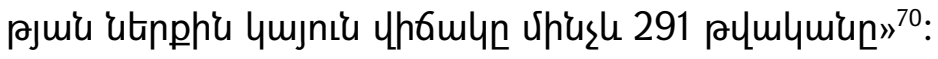

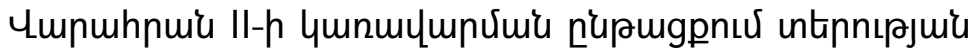

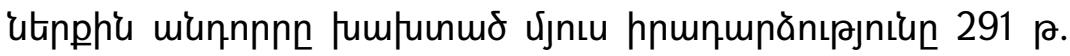

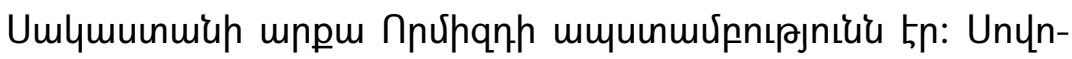

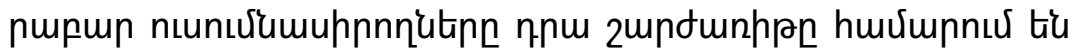

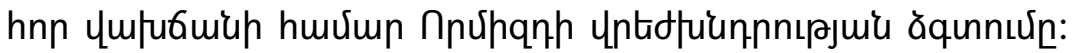

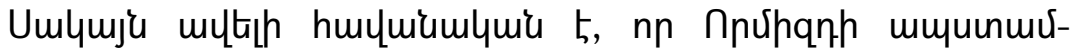

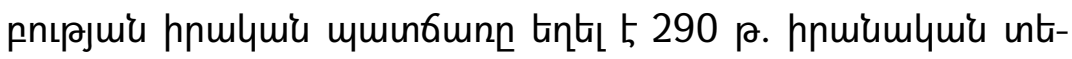

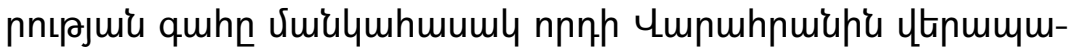

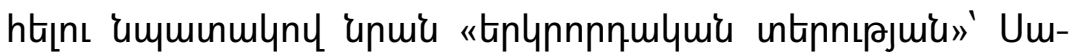

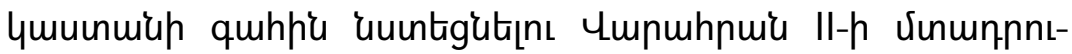

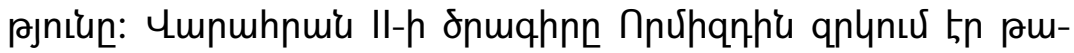

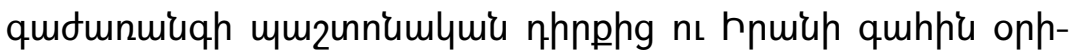

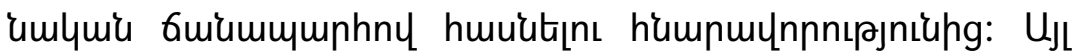

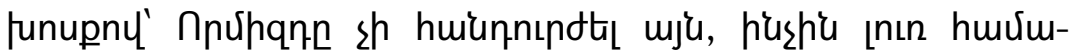

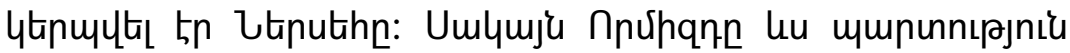

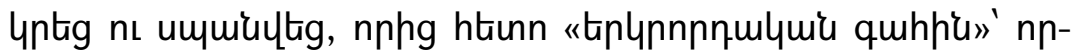

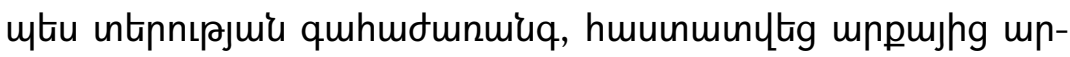
pujh nnпр Чmpmhnuiun:

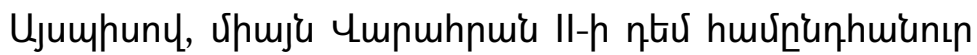

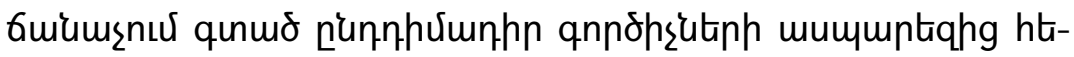

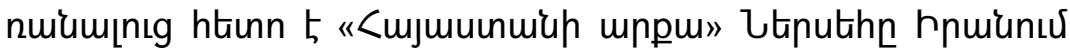

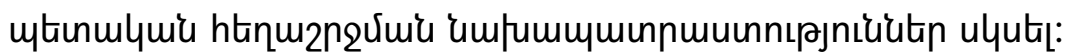

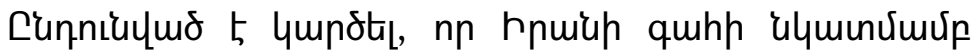

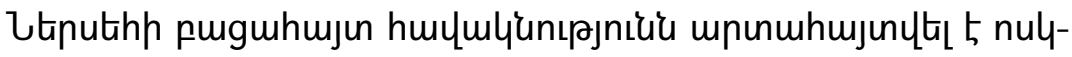

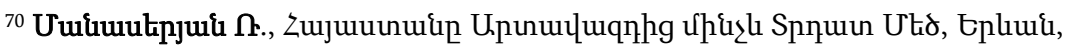
1997, te 132, duid. 1: 


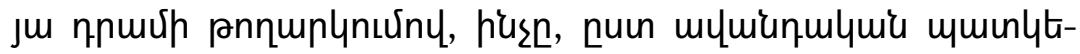

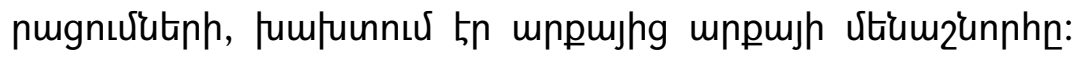

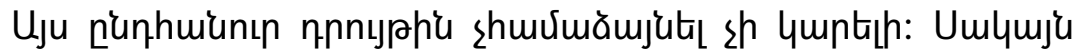

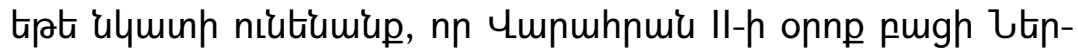

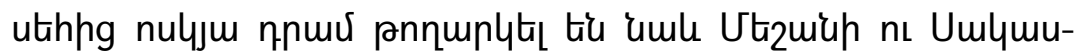

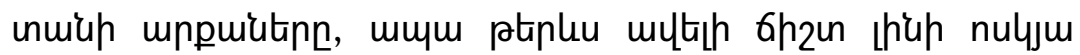

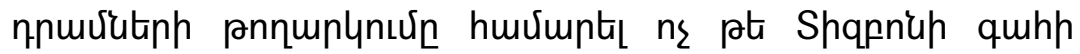

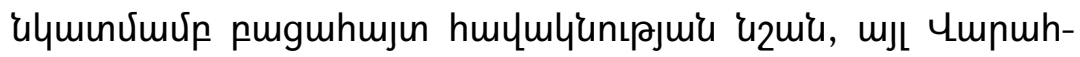

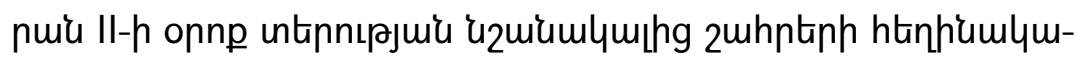

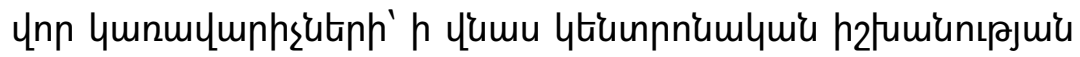

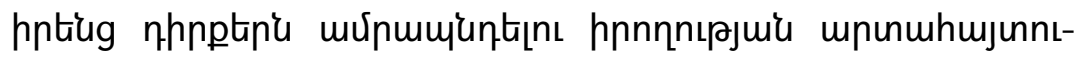
pjnıน:

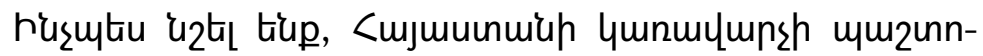

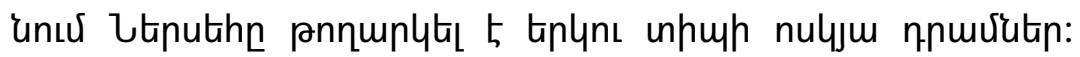

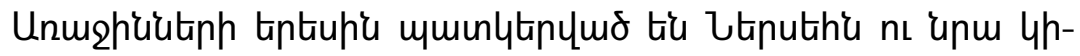
un, hul stiqtiunn unushu 5 Utiputhh wunniu'u ns unpunnnun'

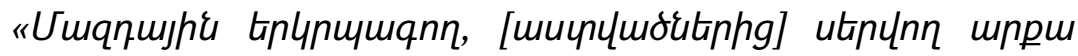

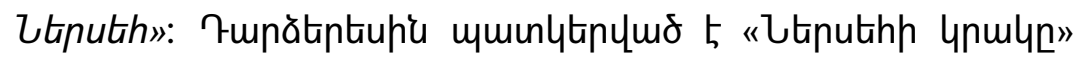

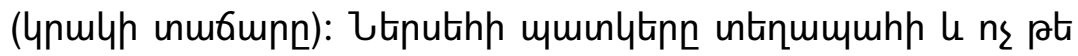

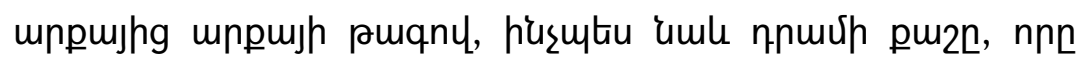

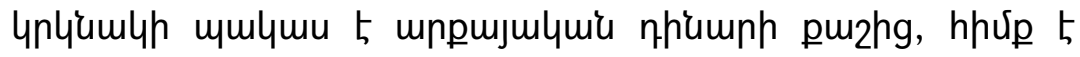

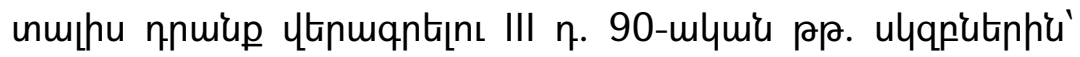

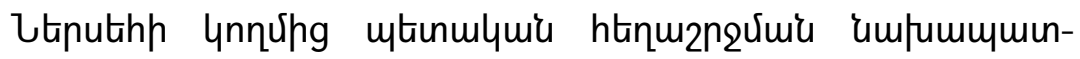

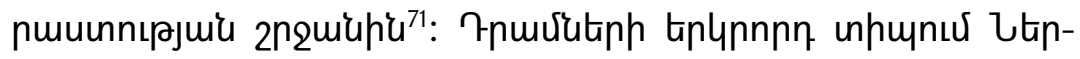

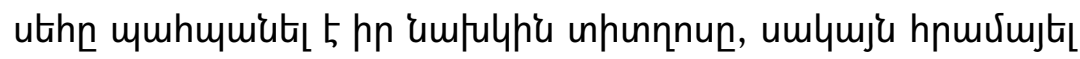

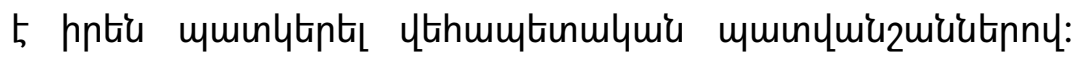

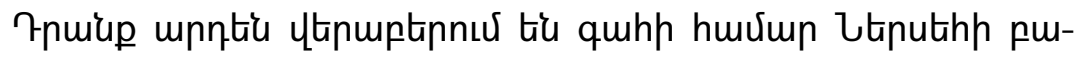

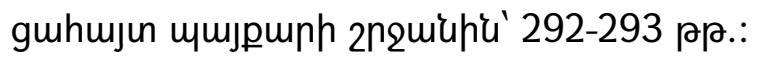

71 Луконин В. Варахран II и Нарсе. Стр. 57. 


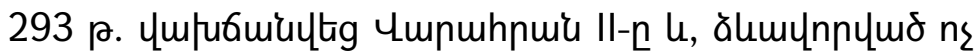

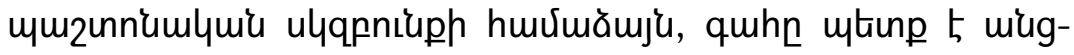

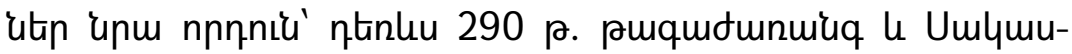

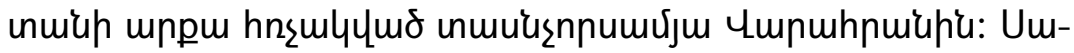

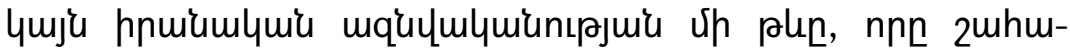

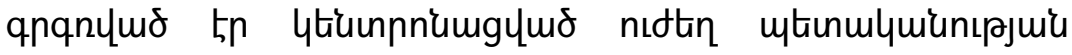

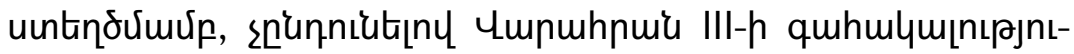

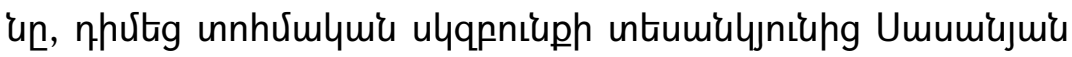

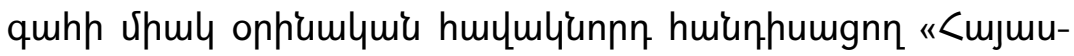

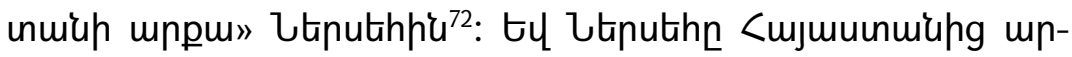
2uutigg Uunntiunniu:

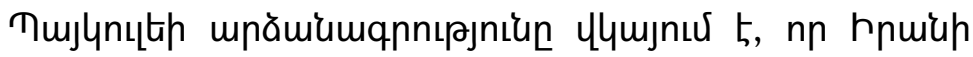

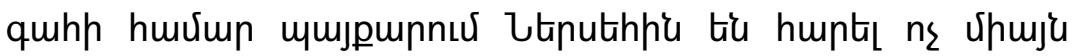

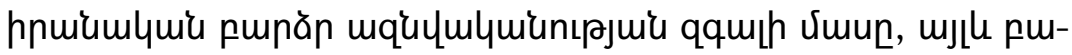

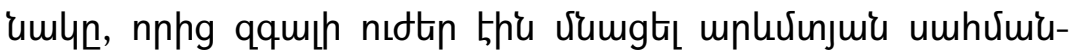

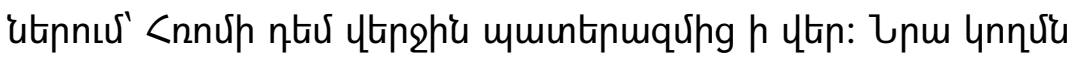

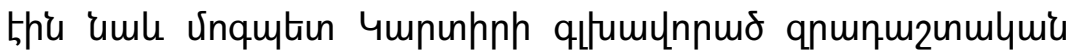

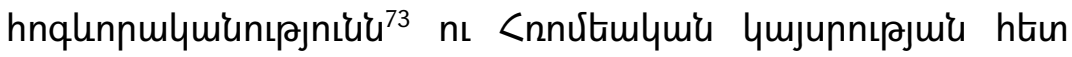

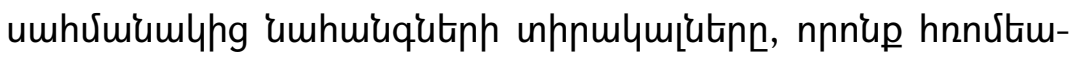

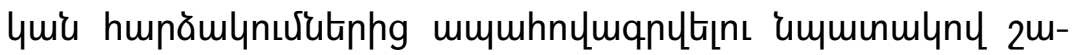

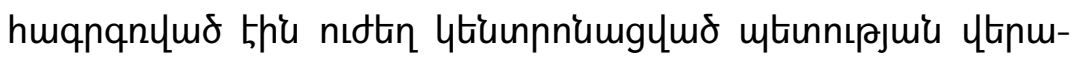

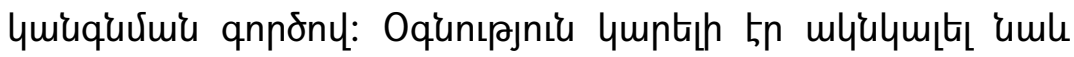

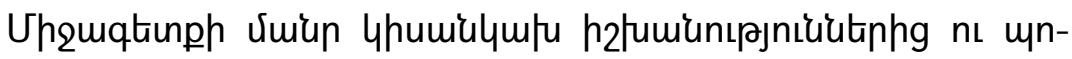

\footnotetext{
${ }^{72}$ Humbach H. and Skjærvø P.O., \{24. u2hu., Uuu 3.1, § 16. «?tuuuuin tiluul

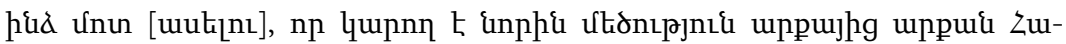

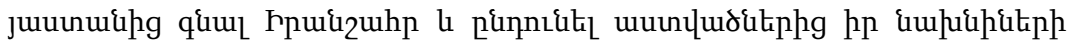

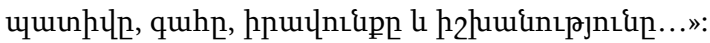

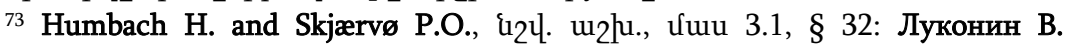
Древний и раннесредневековый Иран: очерки истории культуры. Москва. 1987, стр. 160.
} 


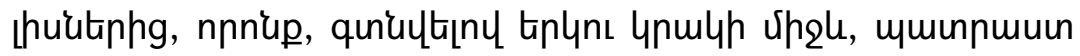

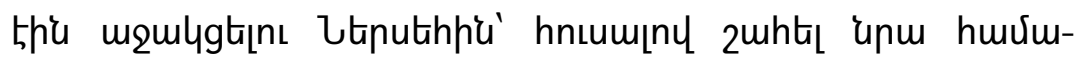

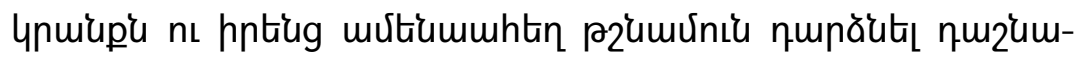
uhg ni hnumumunn ${ }^{74}$ :

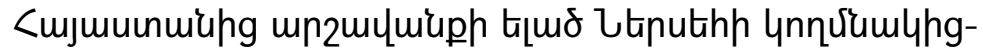

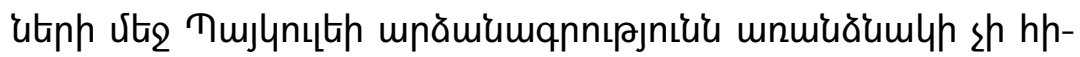

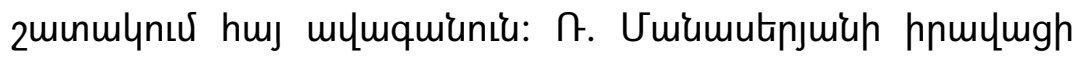

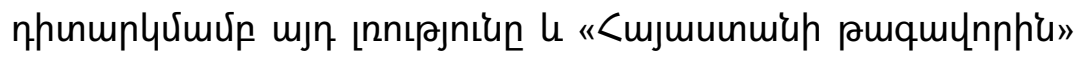

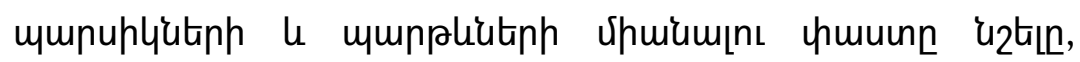

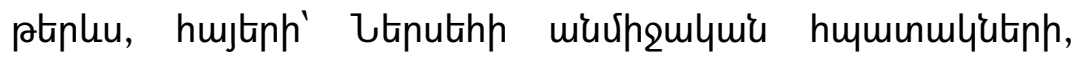

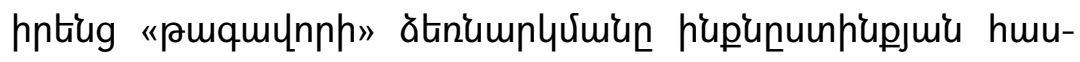

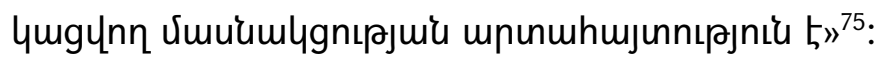

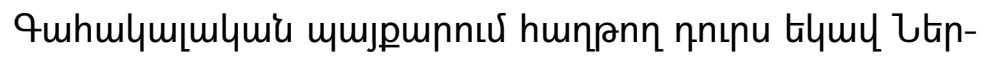

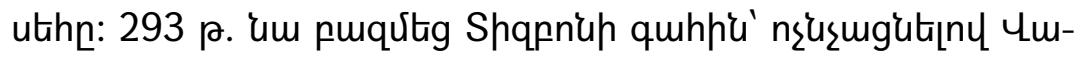

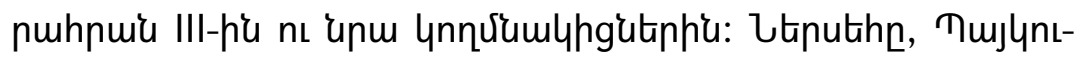

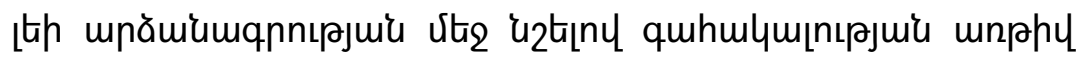

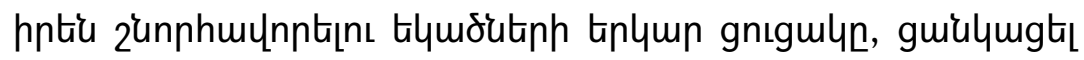

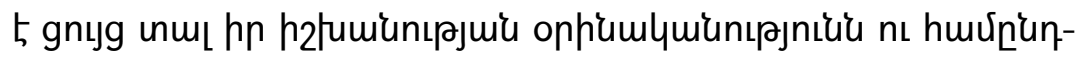

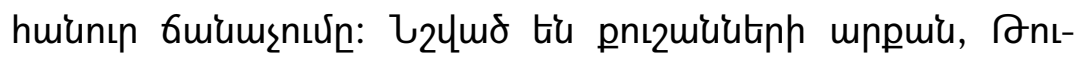

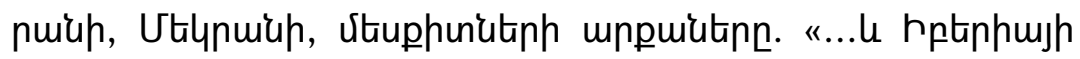

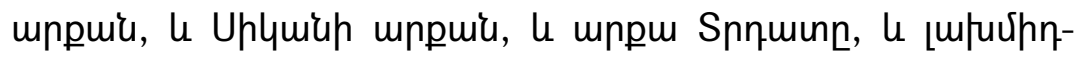

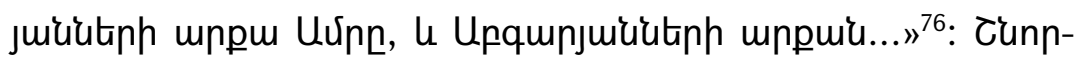

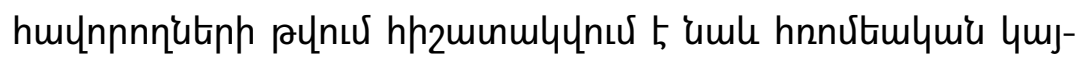

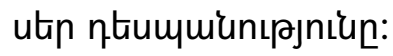

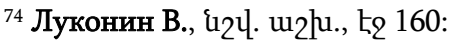

${ }^{75}$ Uuiuuutpjuil ก., \{124. uzhu., to 133 :

${ }^{76}$ Humbach H. and Skjærvø P.O., \{. \{. $4 . u_{2}$ h., Uuu 3.1, § 93:
} 


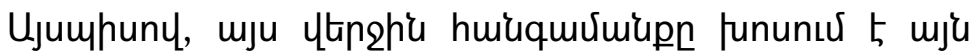

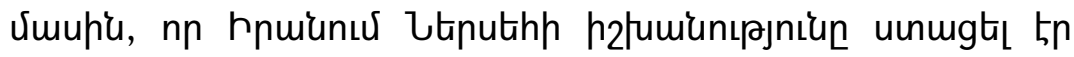
umle únquqqujhí Guiumşnux:

\section{MELIKYAN ARTHUR}

\section{NARSEH SASSANID AND THE STRUGGLE FOR THE REIGN IN PERSIA FROM 274 TO 293}

Keywords: Narseh Sassanid, Persia, Great Armenia, Ctesiphon, Shapur, Hormizd, Ka’ba-ye Zartosht, Varahran, Rome.

In 274 after the death of Hormizd I, the Zoroastrian priesthood and the Iranian high nobility handed the Sasanid throne to Varahrān, the elder brother of Hormizd I, although the other brother Narseh, during the rule of Shāpür I and Hormizd I, had a higher position in the state scale of ranks and was more appropriate for the title of King of Kings. In the following years the Sasanian nobility continued ignoring the rights of Narseh to the throne. After signing the peace treaty with the emperor Probus, in 276/277 Varahran I nominated Narseh, the king of Hindi, Saccas and Turan, the king of Armenia, the country which had lost its strategical meaning. With it Narseh was losing the opportunity of reaching the title of King of Kings in the legal way. Only after the leaders of Iranian opposition were removed, from 282 to 290, Nerseh began an evident struggle for the throne. After the victory in the civil war in 293 the Armenian king Narseh sat on the Sasanian throne. 